\title{
Mainstreaming Eco-Industrial Parks
}

July 2016

Etienne Kechichian Mi Hoon Jeong

\section{\$ World bankgroup Ig KICOX}

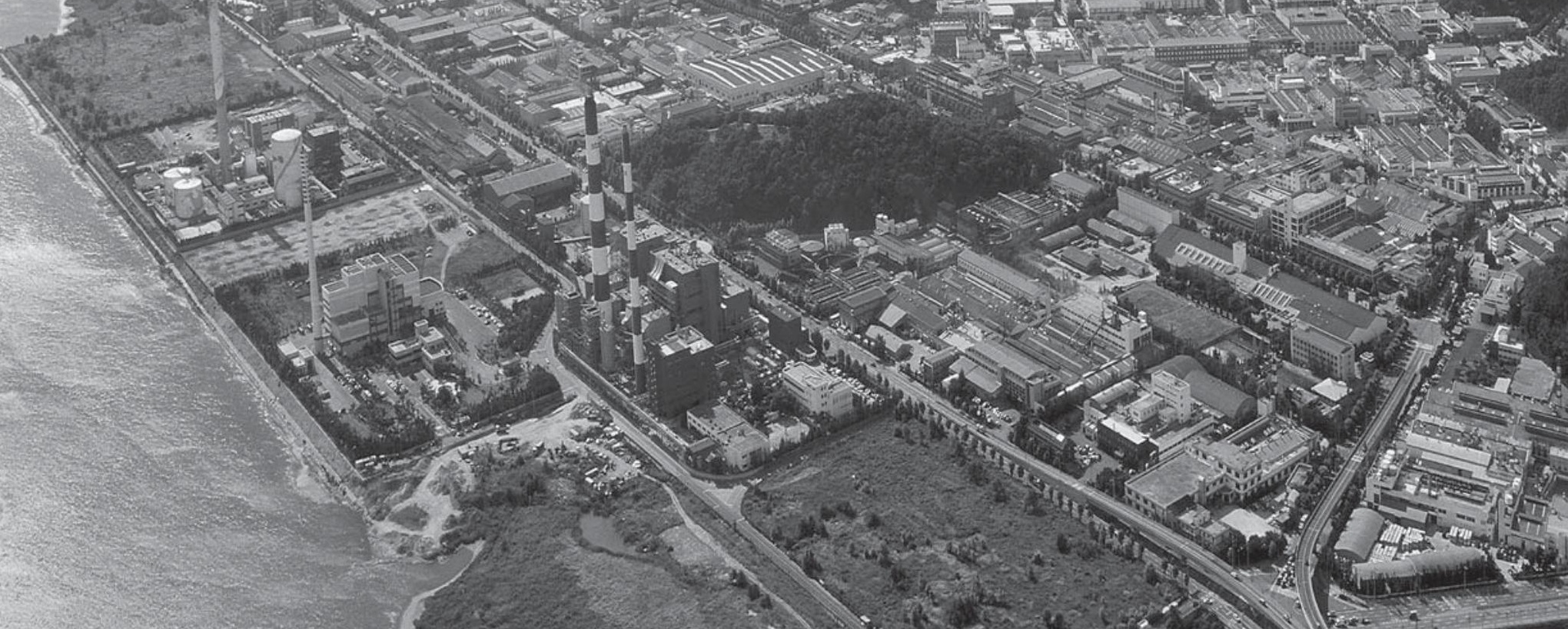




\section{Mainstreaming \\ Eco-Industrial \\ Parks}

July 2016

Etienne Kechichian

Mi Hoon Jeong 


\section{About Trade and Competitiveness}

The Trade and Competitiveness (T\&C) Global Practice helps countries achieve the World Bank Group Twin Goals through rapid and broad-based economic growth, centered on strong contributions from the private sector. For our clients across lower- and middle-income countries and fragile and conflictaffected states, integration through trade and a focus on competitiveness are keys to economic growth. $T \& C$ is meeting growing demand for high-impact solutions that expand market opportunities, enable private initiatives, and develop dynamic economies. Its country, regional, and global efforts help boost the volume and value of trade, enhance the investment climate, improve competitiveness in sectors, and foster innovation and entrepreneurship. This joint World Bank-International Finance Corporation (WB-IFC) team of over 500 staff members offers world-class technical expertise, an extensive global footprint and an updated business model T\&C's day-to-day business is chacterized by intensive learning by-dong strong internal and external partnerships, and a focus on results. The Climate Competitive Industries work within T\&C assists countres address climate action within the manufacturing sector while supporting the

within T\&C assists countries address climate action within the manufacturing sector while supporting the
competitiveness of the sector.

\section{O2016 The World Bank Grou \\ 1818 H Street NW \\ Washington, DC 20433 \\ All rights reserved.}

This volume is a product of the staff of the World Bank Group. The World Bank Group refers to the member institutions of the World Bank Group: The World Bank (International Bank for Reconstruction and Development); International Finance Corporation (IFC); and Multitateral Investment Guarantee Agency (MIGA), which are separate and distinct legal entities each organized under its respective Articles of Agreement. We encourage use for educational and non-commercial purposes.

The findings, interpretations, and conclusions expressed in this volume do not necessarily reflect the views of the Directors or Execulive Directors of the respective institution a included in this work.

Rights and Permissions

The material in this publication is copyrighted. Copying and/or transmitting portions or all of this work without permission may be a violation of applicable law. The World Bank encourages dissemination of its work and will normally grant permission to reproduce portions of the work promptly. For permission to photocopy or reprint any part of this work, please send a request with complete information to the Copyright Clearance Center Inc. 222 Rosewood Drive, Danvers, MA 01923, USA; telephone: 978-750-8400; fax: 978-750-4470; Internet: www.copyright.com.

All other queries on rights and ficenses, including subsidiary rights, should be addressed to the Office of the Publisher, The World Bank Group, $1818 \mathrm{H}$ Street NW, Washington, DC 20433, USA; fax: 202-522-2422

e-mail: pubrights@worldbank.org.

\section{About the Korea Industrial Complex Corporation}

Korea Industrial Complex Corporation (KICOX) is a management and support organization specializing in industrial complexes. It was established by integrating in the industrial complex management corporation in 5 areas, including Korea Export Industrial Corp., established in 1964. Beginning with Guro Industria Complex in 1964, KICOX has continuously created ever more valuable industrial complexes based on paradigm shifts in the concept of an industrial complex for the past 50 years. KICOX is doing various activities to reform as an organization specializing in industry support, such as effective management and operation of industrial complexes, industrial complex renovation, development of eco-industrial parks, development of industrial complexes and expansion of support facilities, industrial complex cluster program and enhancement of supports services of occupant companies.

\section{About the Korea Green Growth Trust Fund}

The Korea Green Growth Trust Fund (KGGTF) is a single-donor World Bank Group program. The $\$ 88$ million program was established in 2011 in partnership with the Republic of Korea. KGGTF finances the uptake of green growth operational technical expertise in an effort to help guide the design of investment projects of clients of the WB-IFC. Economic pathways and solutions that integrate multisector needs, technological innovation, and social inclusion are green growth approaches. KGGTF leverages the realtechnological innovation, and social inclusion are green growth approaches. KGGTF leverages the realgreen growth concepts into investment decisions. 
Eco-Industrial Parks and Competitiveness: From Challenge to Solutions The Growing Demand for Eco-Industrial Parks Integration of "Zones 3.0" and EIPS

nomic Environment

2 Drivers tor EP Development and Growth Greening the Supply Chain Minimizing Operating Costs and Optimizing Resources

3 Mainstreaming EIPs

Green Infrastrtucture and Clean Energy

Main Factors of Success

Common Financing Opportunities

Main Factors of RECP Success

Common Financing Opportunities

Commercial Financing

Commercial

Examples of Savings from Circularity and Symbiosis

Main Factors of Circularity Success

Common

4 Structuring the Approach

Conclusions and the Next Trends of ElPs
The Advent of Climate-Resilient Industrial Paris

1.1 Different Approaches and Similar Goals

2.1 ElPs and the Sustainable Development Goals

$\mathbf{3 . 1}$ Cost Savings through EIPS

3.2 Examples of Savings from RECP $P$ (n)

3.3 Examples of Savings from RECP
3.scal Incentives: An Example from South Africa

4.1 Sustainable Industrial Areas

Figures

1.2 Eco-Industrial Park Drivers for Industrial Complexes in the Republic of Korea

1.3 The Zone 2.0 Framework

1.4 Progression of Zone Development and EIPS

1.6 Proportion of EIPS in and outside of OECD, 2016

1.7 Operating Status of Existing EIPS, 2016

1.8 Type of Eco-Industrial Parks

Development Model

eyond the Zone Framewo

Total Economic Cost of Clima
2050 in South Asia

2.3 The Supply Chain Imperative
2.4
$2.5 x f a m$
"Behind the Brand" Overall Score Change for Climate Change, 2013-16

3.1. Proportion of Impacts trom Different Costs on Chinese Manufacturing Firms

B3.1.1 Roadmap for Low Carbon Growth for Chittagong Export Processing Zone

Structure of the Gujarat Rooftop Solar PPP

3.3 Industrial Symbiosis in Kalundoborg

3.5 How to Carry Out an ElP Project

4.1 An Approach to EIP Development

KICOX Regional EIP Institutional Structure

5.1 Smart Symbiosis Initiatives for Eco City Innovation

3.1 Number and Percentages of EIPS That Have Taken Selected Sustainable Measures

3.2 Areas of Policy Intervention to Support El

B3.2.1 Prioritizing Resource Efficiency Opportunities for Firms in the Chittagong EPZ 
This report is based on the "Eco-Industrial Park 2015" conference in Seoul, Republic of Korea, organized by the World Bank Group and the Korea Industrial Complex Corporation. The event benefited from the support and leadership of Nam Hoon Kang (President, Korea Industrial Complex Corporation); II Joon Park Deputy Minister, Ministry of Trade, Industry and Energy of Korea); and Klaus Tilmes (Trade and Competitiveness Global Practice Director. World Bank Group). The authors recognize the contributions from the speakers of this event Specifically the publication benefited from the discourses of Seogwoong Moon (Chairman of Busan Environmental Education Center, former president of Korean Society of Industrial Ecology):

Hung-Suck Park (Professor of Ulsan University, current president of Korean Society of Industrial Ecology); Rene Van Berkel (Chief Technical Advisor, UNIDO); Alexios Pantelias (Lead of Green Competitiveness, World Bank Group); Anthony Chiu (Professor of De La Salle University); Tsuyoshi Fujita (Director of National Institute for Environmental Studies, Japan); Lei Shi (Professor of Tsinghua University); Katrin Gothmann (Senior Advisor of Environmental and Climate Change of GIZ); Dukgyu Han (Manager of KICOX); and Arnold Tukker (Professor of Industrial Ecology and Scientific Director of Leiden University).

The publication has also benefited greatly from the continuous institutional contributions to this topic from the Korea Industria Complex Corporation (KICOX); United Nations Industrial Development Organization (UNIDO); the Deutsche Gesellschaft für Internationale Zusammenarbeit (GIZ) GmbH; and the University of Ulsan, Republic of Korea The publication and "Eco-Industrial Park 2015 conference" have received funding support from the Korea Green Growh Trust Fund, have which has significanty supported the global agenda on eco-industial parks.

Guidance was provided by the book's peer reviewers Sherif Muhtaseb, Douglas Zhihua Zeng, Gokhan Akinci, and Sumit Manchanda. The publication as completed under the leadership of Alexios Pantelias, Lead for Green Competitiveness of the World Bank Group.

S. D. Williams provided substantive copy editing and the team benefited from the services of the World Bank's GSDTI English Editing Team. The design and typesetting of the report was carried out by Tanitim with guidance from Beril Benli. 


\section{Overview:}

\section{Eco-Industrial Parks}

and Low-Carbon Zones in

the Future of Industrial Development

Special Economic Zones have played an important role in the economic growth of many developing and advanced-developing nations including Bangladesh Brazil India Republic of Korea Thailand Turkey and Vietnam. These zones provide tailored infrastructure and business services, and they have become succesful model for large scal job creation, transer of skills and technology, export diversification, and industrial development led by foreign direct investment.

They have also presented challenges. Throughout their long history, various kinds of industrial parks and economic zones have been seen by some as a controversial development model based on fiscal incentives and export requirements. They have gradually evolved to provide efficiently serviced industrial land for industries. Newer models of zones, or "Zones 3.0," have become more flexible, focused on providing highly efficient services infrastructure, and they have become more integrated into the global economy.

Until recently, sustainable business practices were widely ignored or overlooked by most of the enterprises operating in such zones. Due to challenges related to global climate change and a decrease in the stability of resources such as fuels, ecological and social factors are becoming crucial in industry's plans to remain competitive. Governments and the private sector have become supportive of a more modern and sustainable investment regime for industrial zones. This regime is based on the following:

1. Effective and measurable application of a climate change agenda by national governments

2. Buyers' preference for sustainable products

3. Increased productivity at the firm and park level

In the next era of industrial zone development, sustainability and eco-industrial growth play paramount roles in minimizing environmental and social risks while generating profits for firms. This combination helps governments scale-up and leverage sustainable infrastructure to fulfill their commitments to meet the UN Sustainable Development Goals and other international climate actions.

There are tangible drivers behind this changing paradigm of industrial zones. There is also a visible shift in the procurement preferences of the leading global buyers whom the zone enterprises primarily cater to, in the procurement preferences of the leading global buyers whom the zone enterprises primarily cater to, especially in he ligh manufacturng sector. For example, KEA plans to reduce the carbon footplint or its entire supply chain and use 100 percent renewable energy for its operations in the near future (IKEA, n.d.). These multinational buyers are showing strong preferences for greener and more sustainable supply chain management that compels suppliers to produce in an environmentally compliant, resource-efficient, safe, and socially responsible manner. The growing availability of reduce-reuse-recycle technology for industrial wastes has also heightened the pressure on industries to improve their management of waste and resources and look for mechanisms to grow and operate in a symbiotic fashion.

Efficiency and the strategic conglomeration of firms will enable companies to take advantage of joint infrastructure, efficient management of operating risks, and improved resilience to climactic conditions. The world's urban population increased from 43 percent in the 1990s to 54 percent in 2014 (UN 2014), and this forced a closer collaboration between industrial spaces or zones and residential areas. This trend continues to grow.
Within this changing reality, the concept of eco-industrial parks (EIPs) and low-carbon zones has recently entered the scene. The trend toward EIPs has been growing organically in most developing countries. Although consensus is missing on what definitively constitutes an EIP, World Bank preliminary research has identified over 254 operating or planned zones or parks that would likely fit a stringent definition. The bulk of these EIPs employs some level of ecological and sustainable practices, but further research is needed to find out what practices are actually employed and how well they work in particular circumstances.

It has become urgent to explore these models and to understand the contexts in which they can tackle the environmental and ecological challenges of our times while retaining their role as production hubs and growth centers. Development Institutions like the World Bank, IFC, United Nations Industrial Development Organization, the Deutsche Gesellschaft für Internationale Zusammenarbeit (GIZ) GmbH, and Korea Industrial Com thex Corporation (KICOX) have been leading the drive to promote these concepts in emerging economies, while countries like the Republic of Korea, Denmark, China, Japan, and Germany have been at the forefront of their implementation.

This report, based primarily on a global conference "Eco-Industrial Parks 2015," held in Seoul, Republic of Korea in October 2015, provides the latest thinking on eco-industrial parks, bringing together experiences from different countries and providing a vision on how these initiatives can be scaled up or mainstreamed. It will provide policy makers with insight conceptualizing EIPs and what different factors need to be considered in putting together an EIP program. The report builds the basis for further development of guidelines and step-by-step approaches on how to develop a national program on EIPs.

References

ssponsibilityclimate_change/

United Nations, Department of Economic and Social Affaris, Population Division (2014). World Urbanization Prossects: The 2014 Revision, Highlights (ST/ESA/SER.A352).

\section{Abbreviations}

\begin{tabular}{|c|l|}
\hline ECA & Enhanced Capital Allowances \\
\hline EIP & eco-industrial park \\
\hline IFC & International Finance Corporation \\
\hline GHG & greenhouse gas \\
\hline GEF & grid emission factor \\
\hline GIZ & Deutsche Gesellschaft für Internationale Zusammenarbeit (GIZ) GmbH \\
\hline KICOX & Korea Industrial Complex Corporation \\
\hline OECD & Organisation for Economic Co-operation and Development \\
\hline PBI & performance-based fiscal incentive \\
\hline PPP & public-private partnership \\
\hline RECP & resource efficiency and cleaner production \\
\hline SDG & Sustainable Development Goal \\
\hline SEZ & Special Economic Zone \\
\hline tCO $-\mathrm{-}-$ & tons of carbon dioxide (or equivalent) \\
\hline UNIDO & United Nations Industrial Development Organization \\
\hline
\end{tabular}


1

\section{Eco-Industrial Parks and \\ Competitiveness:}

From Challenge to Solutions

The Growing Demand for Eco-Industrial Parks

Special Economic Zones (SEZs) have been a go-to option for industrial development for about 130 countries around the world, with varying degrees of success. ${ }^{1}$ They are essential parts of policy packages that provide serviced industrial land to investors. However, a critical challenge these zones have faced, due to their nature of conglomerating industries, is ineffective management of environmental pollution and labor issue, such as of conglomerating industries, is ineffective management

Figure 1.1

Industrial Environmental Issues

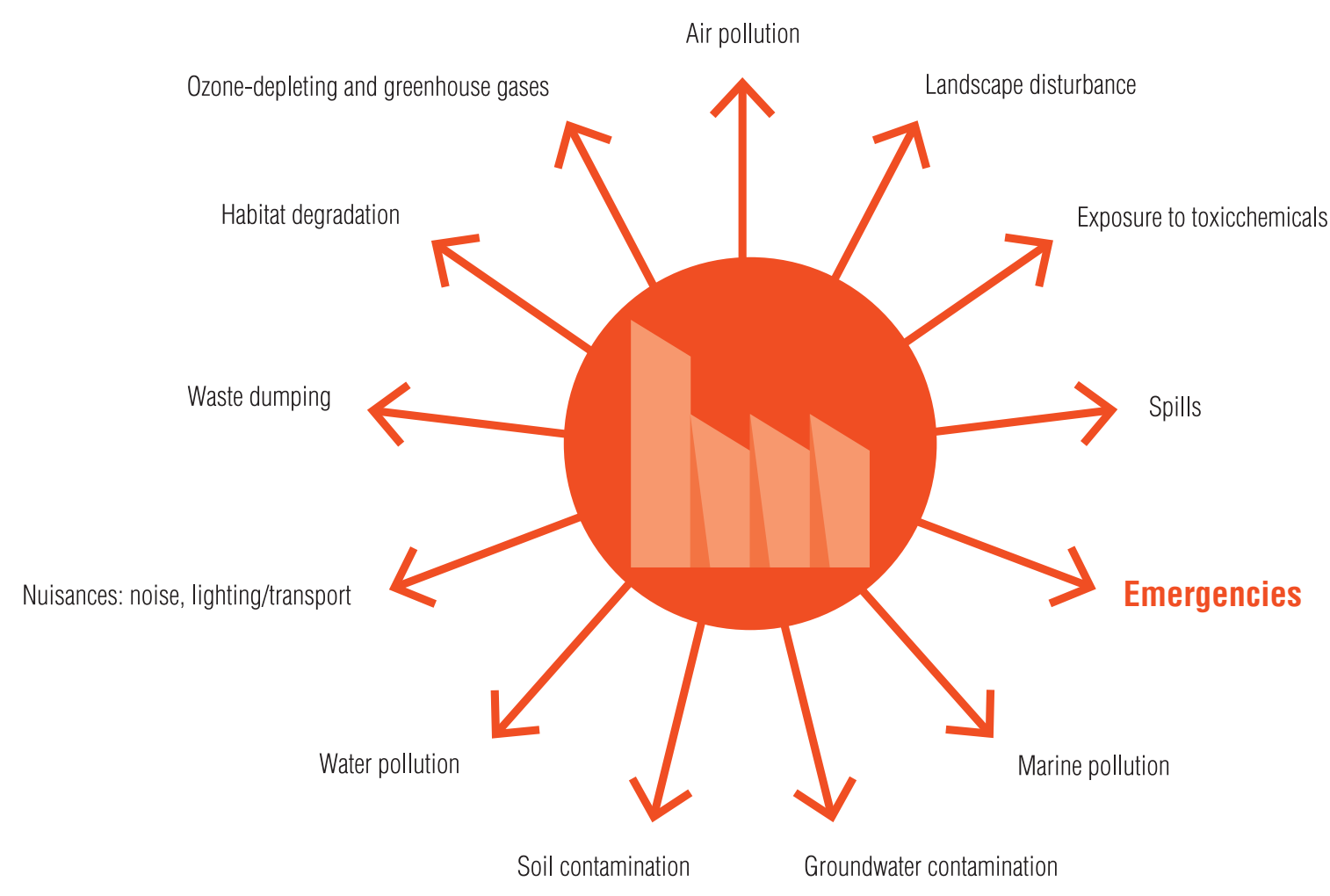

Figure 1.2

Eco-Industrial Park Drivers for Industrial Complexes in the Republic of Korea

$\begin{array}{r}\text { Pollution } \\ \text { Air/waterground and } \\ \text { odor/traffic jam etc. }\end{array}$
Industry
Resource and
energy cost te.

Source: KCOX 201

The concept of eco-industrial parks developed mostly in Northern Europe, in places such as Kalundborg in Denmark and Kymi and Harjavalta in Finland in the 1960s, and eventually evolved toward more planned models, such as those in China and the Republic of Korea in the 2000s. ${ }^{2}$ More recently, with an increased focus from development institutions like the World Bank, International Finance Corporation, United Nations Industrial Development Organization, and Deutsche Gesellschaft für Internationale Zusammenarbeit, there has been a considerable scaling up in the application of eco-industrial park (EIPs) in developing countries.

The dramatic shift in industrial zone management trends can be attributed to a number of drivers in emerging markets:

- Demanding more sustainably sourced and produced products

- A desire for zone developers and operators to provide additional services to tenants and differentiate themselves from other types of industrial land

- Growing pressure from external stakeholders such as the government, regulators, nongovernmental organizations, and civil society organizations forcing the zones to operate in an environmentally responsible fashion

- Voluntary action by industry to self-regulate and increased focus on practical corporate social responsibility efforts

These, among other factors, have created a demand for further knowledge and information on EIPs and their approach and functions. Most important, there is a need for a new and global framework for EIP development. The EIP approach allows developers and managers to provide value-added services to their tenants and a sustainable infrastructure that investors can to builds, reducing their initial investment and operational costs. There is a large financing gap, and thus an opportunity, for the financial sector to 
support the infrastructure and investment needs in industry's climate change agenda. While these drivers have contributed to a shift in zone management trends, profitability and financial viability remain a zone operators' main objectives

Box 1.1

\section{Different Approaches and}

Similar Goals

As part of SEZs, EIPs cover a wide spectrum of approaches, all leading to a more sustainable industria development Depending on the different prioritios for each individual park, EIPs may be given different names. These could be inflenced by (i) the nationat industial area framework (for example, industrial zones versus parks) and (ii) priorities of the country or zone operator (for example, greenhouse gas emissions reduction versus ecology or waste).

Low-carbon zones or industrial parks lower carbon emissions within the industrial area through rigorous greenhouse gas emissions calculations and annual target setting. Measures at the zone (or park) and firm level focus on the largest emissions reduction opportunities.

Eco-industrial zones or parks focus on ecologica improvements in terms of reducing waste and improving the environmental performance of firms. The Republic of Korea uses this term primarily for its work on industria symbiosis.
Green zones reduce resource use within infrastructure and tenant firms, as in an EIP, and also focus on generating investments in green manufacturing and services.

Sustainable industrial areas focus on the management level of an industrial zone or park with the intent to guide the industrial area as a whole to become more sustainable. Although this approach does not deal with the individual companies, the sustainability framework at the park level is likely to initiate and promote positive changes on the company level as well.

Eco-towns refer to an urban planning and environmenta management approach where industries located in the designated area pursue synergies in resource utilization, waste management, environmental preservation, resour efficiency within their manufacturing processes and between the industries, and promotion of industrial and economic development (GEC 2005).

Circular economy zones (or circular transformation of industrial parks) aim to promote resource efficiency. waste management, and emissions control in firms, zones, and regions through a circular economy pattern.
Integration of "Zones 3.0" and EIPs

SEZs have played an important role in the economic development of several countries, especially in the developing world. From what were called Zones 1.0 to the current and emerging version, Zones 3.0, industrial zones are heading toward a more comprehensive, integrated eco-system approach to economic development. This approach synthesizes the experiences of zones 1.0 and 2.0 and works to create an integrated solution that addresses global trends in low-carbon growth and trade and investment policies with domestic institutional frameworks, industries, and communities.

Approaches for Zones 1.0 focused on industrial zones as export-processing zones that could promote exports and attract foreign direct investment. Zones would usually enjoy tax exemptions in order to promote export competitiveness and were typically funded by the government with separate customs areas recognized under the Kyoto Convention.
Though funded by the government, the zone authorities had little power to work in collaboration with other government bodies, limiting the development of policies that could enhance the operations

Figure 1.3

The Zone 2.0 Framework

Physical features

- Integrated, mixed-use zones

- Growth pole-sector/lluster focus

- Purpose-built facilities

- Low-carbon/green focus

Development approach

- National implementation strateg

- Public-private partnerships

- Business driven

Policy framework

- In touch with market (Market test and PPPS)

- State of the art regulatory environn

- Multimarket, not just export

- Deregulation and demonopolization

- Shift towards smart incentives

- Adherence to universal labor and

environmental standards

- Link to local communities

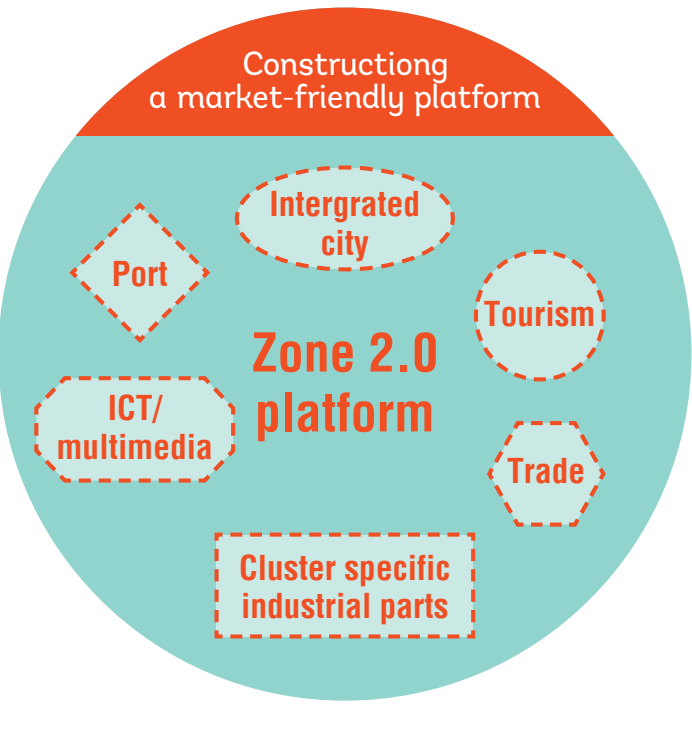

Mutlisector and multiuse with more focus on linkages and global standards
Institutional framework

- Zone authority regulates activities

- Clear delineation of roles and responsibilities

One-stop shop for zone regime regulation

Changing global and regional contexts led to a shift in how zones were viewed and operated. Zones 2.0 would create more integrated, multisector, and multiuse SEZs that could focus more on linkages and global standards (Figure 1.3). The SEZ approach designed integrated, mixed-use zones that at times had a sectoral or cluster composition. Linkages to national development and policy were made as zones were addressed in national implementation strategies and public-private partnerships were formed.

Under this model, zones were operated with market demand in mind and shifted from a purely export focus to multimarket policies. Zone policies and regulations became more structured, with implementation of smart incentives and adherence to universal labor and environmental standards. 
Regulatory enforcement through the zone authority, clarified roles and responsibilities between different actors, and a larger role played by the private sector helped to overcome some of the limitations of the earlier model of economic zones.

The lessons learned from the experiences of zones 1.0 and 2.0 have shown that simply setting up a zone is not a comprehensive solution; without the right policy and institutional frameworks, zones may fail. In addition, zones should be operated within the framework of national development policies and community development, not in isolation from these (Figure 1.4).

Figure 1.4

Progression of Zone Development and EIPs
Types of
economies

Corresponting
indulustrial 200 e

EIP objective
Factor-driven-1.0

Basic real estate services

and infrastructure

\section{Enviormental compliance}

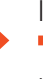

Innovation-driven-3.0

gher-technology manufacturing

$\rightarrow$

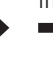
$\rightarrow$
Enviromental managment Eorin
Efficiency-driven-2.0

EIPs in the Changing Climate and Economic Environment

Precursors of EIPs can be found as early as the late nineteenth century in European industrial zones. Howeve they truly began developing in the post-World War Two period in Denmark, Germany, and Finland in an unplanned, organic fashion as a result of resource limitations and high energy costs. For the most part they took the form of industrial symbiosis and efficiency measures. In the 1990s, other European countries and non-European developed states such as the United States, Japan, and Canada started incorporating EIP concepts, partially or fully, in their design of industrial zones. Some developing countries, such as China and India, began to do the same. The focus of EIP interventions was mostly on waste management and pollution mitigation in this period.

In the early 2000s, Japan, China, and the Republic of Korea expanded their ElP efforts, supporting them with national policies as a means to boost their competitiveness in global markets. By the century's second decade. EIPs became a prominent global tool for new industrial zones, whil retrofit activities continued in over (20 countries (Fig 15). In 2010 the development and SEZ retrofit projects in the pipeline globally.

Within the Zones 3.0 approach lies a greater demand for EIPs, which offer additional services and benefits to industrial park and zone tenants, developers, and operators. As EIPs are intimately tied to industries and competitiveness, the need for these types of parks comes down to demand creation and business benefits. These have sometimes not been obvious. However, with an increased emphasis on mitigating climate change on a global scale and a more tangible approach to carbon pricing, the economics of climate action are shifting. This entails a greater obligation for businesses and chief executive officers to address climate change within their operations and supply chain.

Figure 1.5

The Global Growth of ElPs

Zones 3.0 builds on these lessons and takes a more coordinated and integrated approach; it moves aw from zones in seclusion toward an integrated economic communities approach. Central to the Zones 3.0 approach is the effort to connect seemingly disparate activities to create linkages that can create
synergies and enhance efficiency. Zone operations consist of multiple components such as infrastructure and logistics, land use and urban planning, environmental and social protection, education, and trade and investment. Each of these activities is regulated and implemented by different authorities. For example, logistics would be a matter for transportation authorities while green growth would be under the environmental authorities. In Zones 30 zones are understood to contain these and more components that need to be integrated in order to create a comprehensive industrial infrastructure.

Zone 3.0 aims to do more than simply export goods. Its goal is to attract investment, reduce costs, generate income and employment, reduce dependence on nonrenewable energy sources, improve productivity, promote sustainable socioeconomic national development, create linkages with global value chains, and much more. Zones 3.0 , in essence, takes on the role of integrating policies and markets and creates both hard and soft industrial infrastructure.

Zone 3.0 provides the platform for EIP mainstreaming. Some of the main attributes of EIPs include, but are not limited to, increased use of renewable energy, implementation of energy-efficiency measures, construction of buildings and factories using green buildings codes, waste-reuse and recycling systems, material and utility linkage through industrial symbiosis, clean technology research and developmen demonstration, and deployment. All these actions bring direct business benefits to the enterprises: savings of utility cost, higher capital efficiency, cleaner and leaner production, and greater acceptability of products to global buyers. By focusing on a more integrated approach with enhanced green infrastructure services, the SEZ operator in coordination with stakeholders can provide a critical platform for sustainability to its tenants.

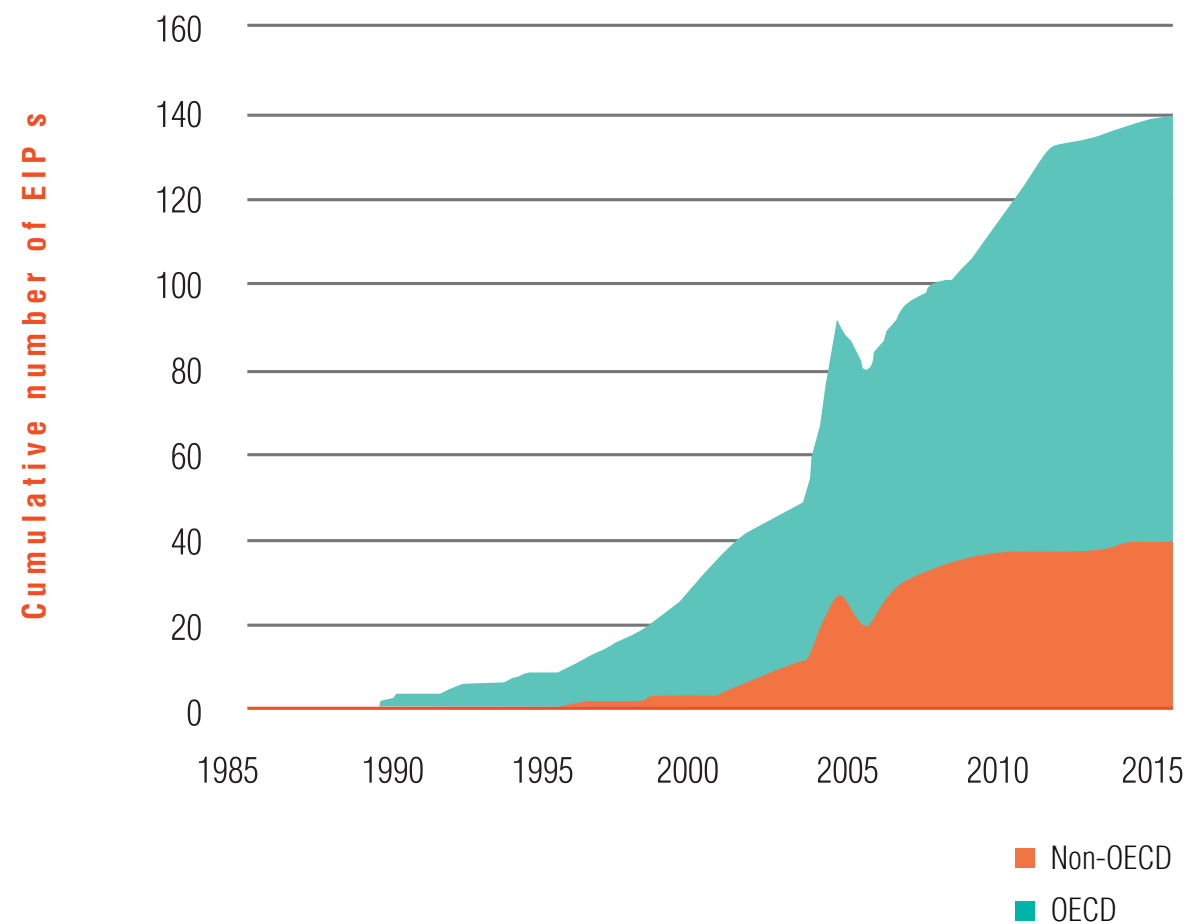

- OECD 
Within the changing economic reality of climate change, the concept of EIPs and low-carbon zones has recently entered the scene. The trend of developing EIPs has been picking up organically, mostly in developing countries. Whereas in 2000 only 10 percent of EIPs were in non-OECD countries (estimated at 11 EIPs), this total is now an estimated 30 percent (Figures 1.5 and 1.6). Although a shared definition of an EIP does not yet exist, World Bank preliminary research has identified over 254 operating or

planned EIPs of which 77 percent are operational. (Figure 1.7). The bulk of these EIPs employ some level of ecological and sustainable practices, but further research is needed to find out what practices are

actually employed. Analysis also found that around 80 percent of EIPs are industry-oriented zones. In

terms of how EIPs are created, most result from retrofitting existing EIPs (59 percent), followed by planned

development of EIPs (34 percent). A very small amount are organically or nonplanned developments of

EIPs (Figure 1.9).

Fiqure 1.6

Proportion of EIPs in and outside of OECD, 2016

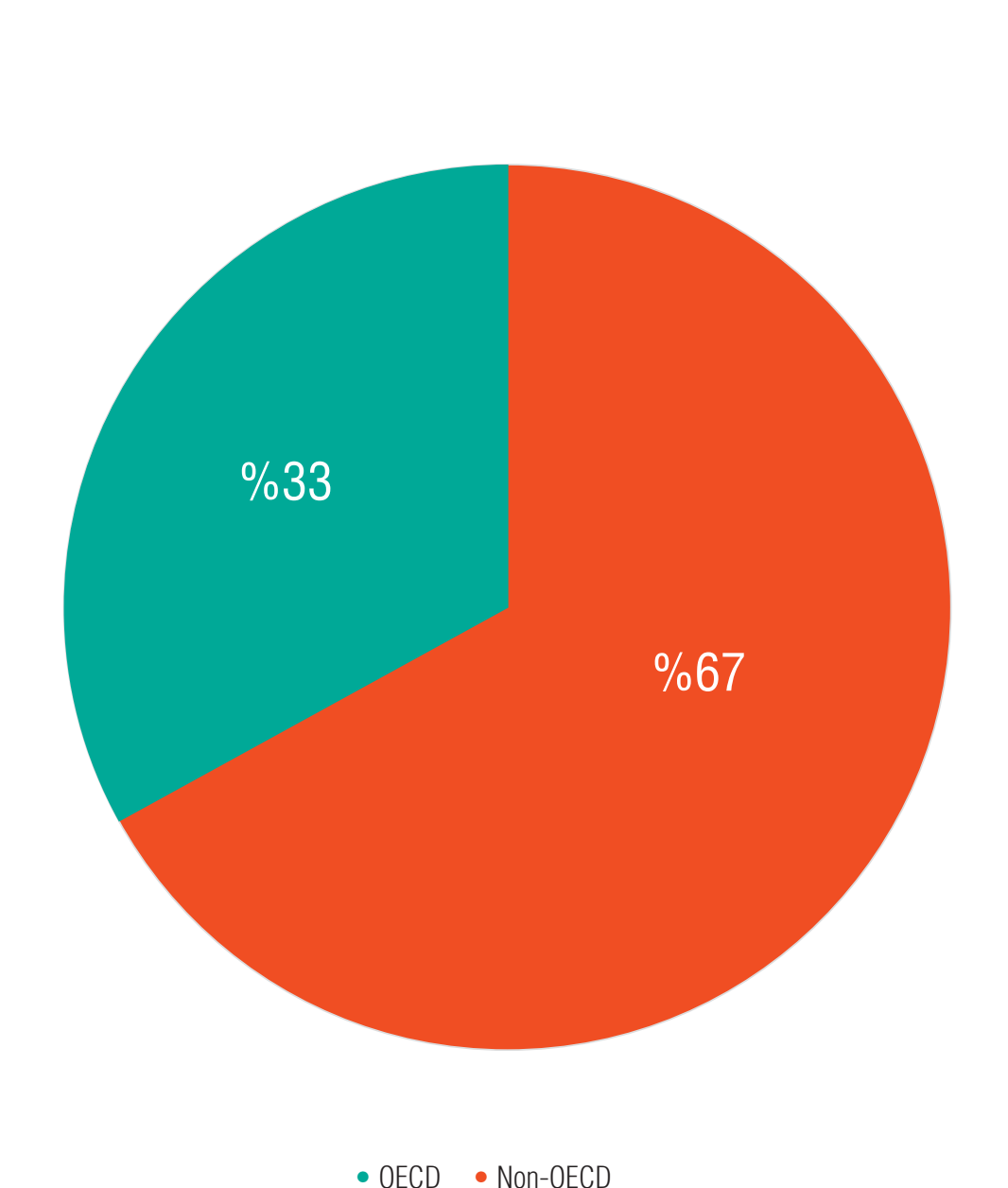

- OECD • Non-OECD
Figure 1.7

Operating Status of Existing EIPs, 2016

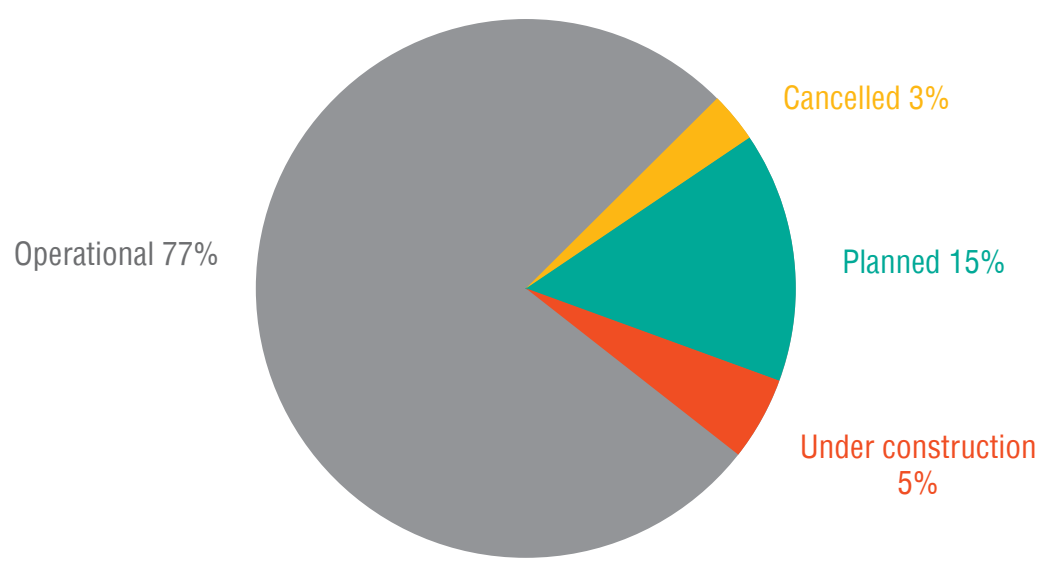

Source: World Bank, UNIDO, GII 2016,

Figure 1.8

Type of Eco-Industrial Parks

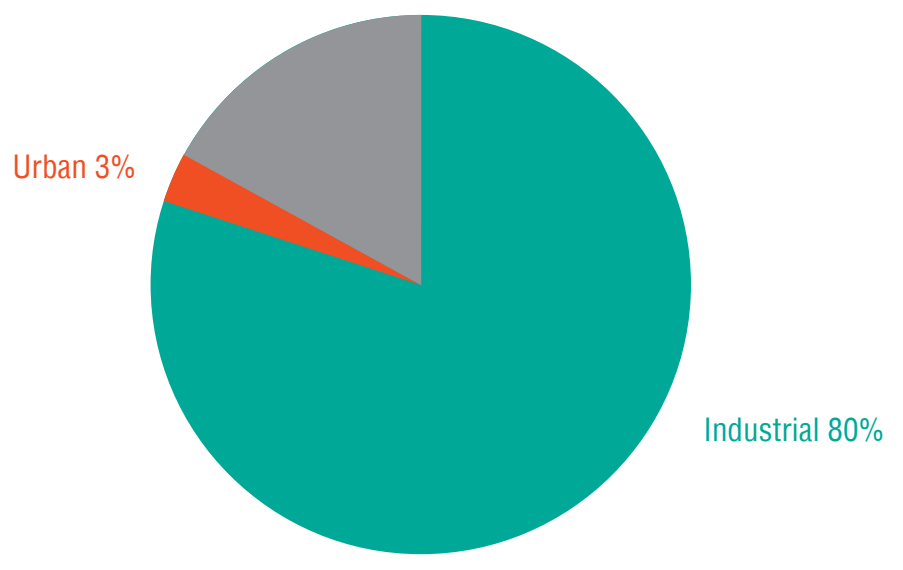

Figure 1.9

EIP Development Model

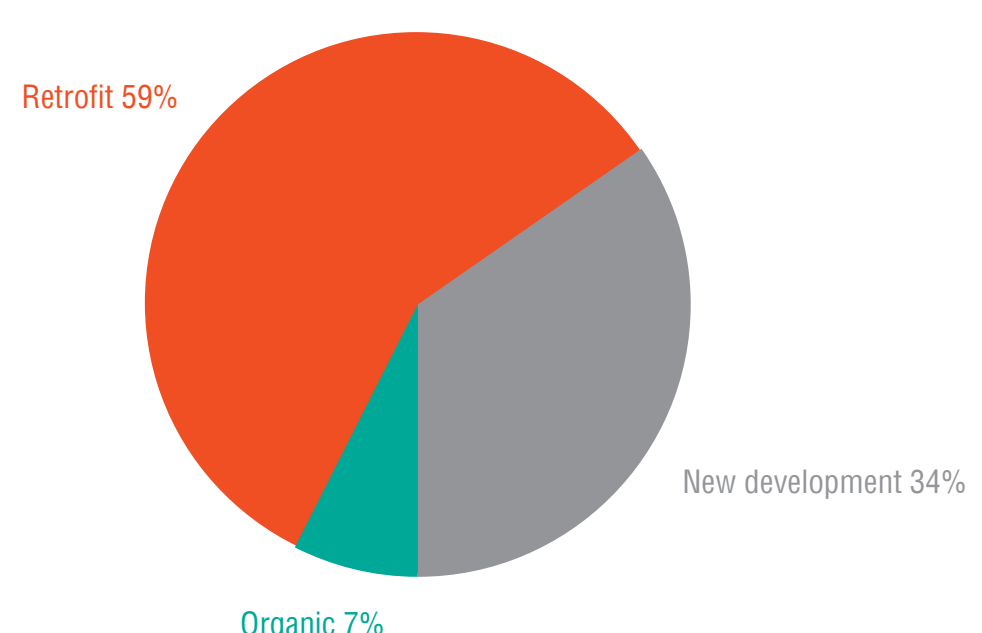


Countries like the Republic of Korea have progressively integrated EIPs into their industrial complex framework. Employing 2 million people and being responsible for US\$45 billion in exports, the Republic of Korea's industral parks have implemented the EIP model since 2005. This has helped them transition into innovation-led industrial parks. The EIP model prompted firms to invest over US\$520 million (623.71 billion won) in energy efficiency, industrial symbiosis, waste management, and other eco-friendly investments. To date, this has helped firms save over US\$554 million and generated US\$91.5 billion (1,102.42 billion won) in new revenue ${ }^{4} \mathrm{As}$ of December 2014, 60.6 percent of the Republic of Korea's companies are managed by the Korea Industrial Complex Corporation (KICOX), which accounts for 52.5 percent of the country's employment, 54.5 percent of production, and 49.4 percent of exports.

The growth of the EIP model is expected to increase as the struggle against climate change increases and governments, cities, and SEZs take a more active role in climate action. To address climate change issues as
well as to provide a catalytic platform to enhance business applications and opportunities for climate friendly investment, coutres like Egypt, Vietnam, and Tukey are now looking to scap up their EIPs in the near fuly This new wave of EIPs will be m, Ver This new wave of EPs wil be more compen This puclcailon and This publicalion and void in this context to provide a mo comprehonsive understanding of the apprach and the opportunities creates for policy makers in order to mainstream the EIP concept in SEZ development and operations.

References

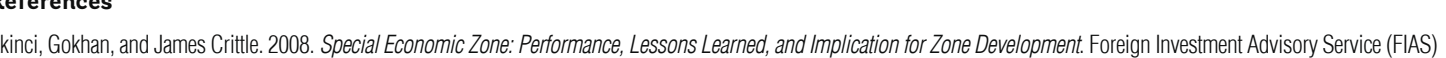
occasional paper. Wastington, DC: World Bank

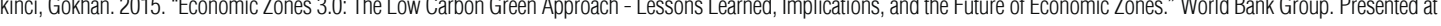
the Eco-Industrial Park 2015 Conference.

Boyenge, Jean-Pierre Singa. 2007. LL Database on Expoot Procossing Zones (Revised). In: LLO Working Papers.

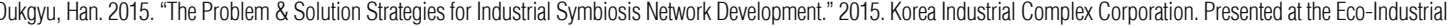
Park 2015 Conference.

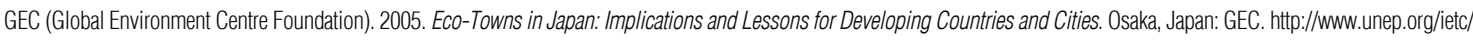

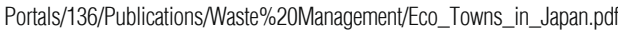

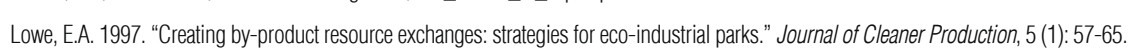

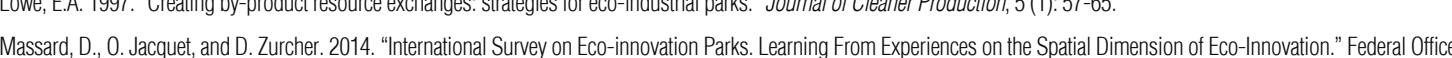

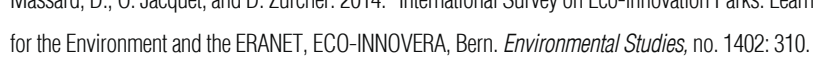

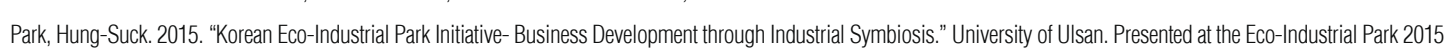
Park, Hung S

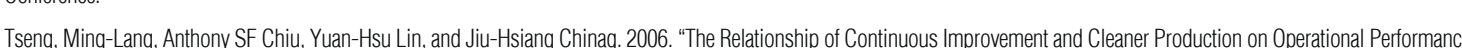

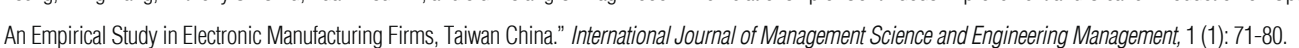

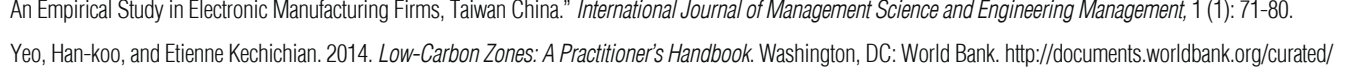
Yeo, Han-Koo, and Eteienne Kechichilin. 2014. Low-Carbon Zoneses.

Notes

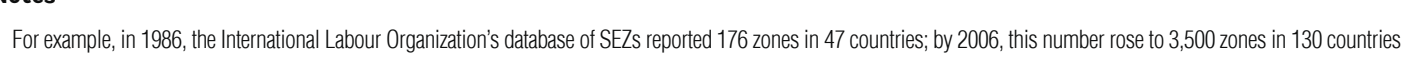

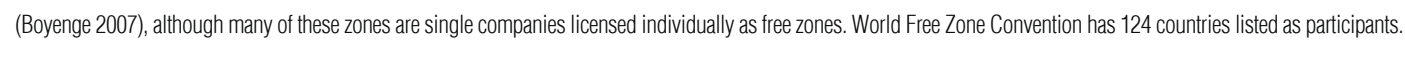
This repor has theretore used 130 as a genental number

The widely ssed detinition of a n eco-inustrial park, used both by UNDD and the World Bank Group, is from Lowe (1997) of the Asian Development Bank, who stated,

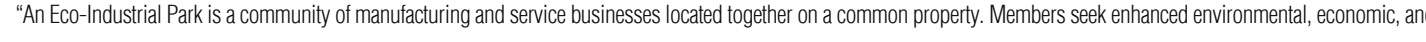
social pertormance trirough coliaboration in managing environmental and resource issues."

The Figures for these graphs were derived primarily from Massard, Jaccuat,Zürcher, 2014 and supplementeded by desk research, inteviews and internal Wordd Bank Group sources

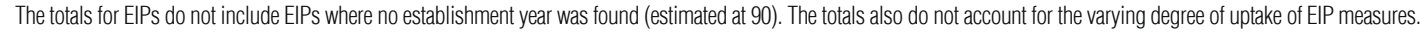
“These numbers are accumulated values from 197 business cases implemented since 2005

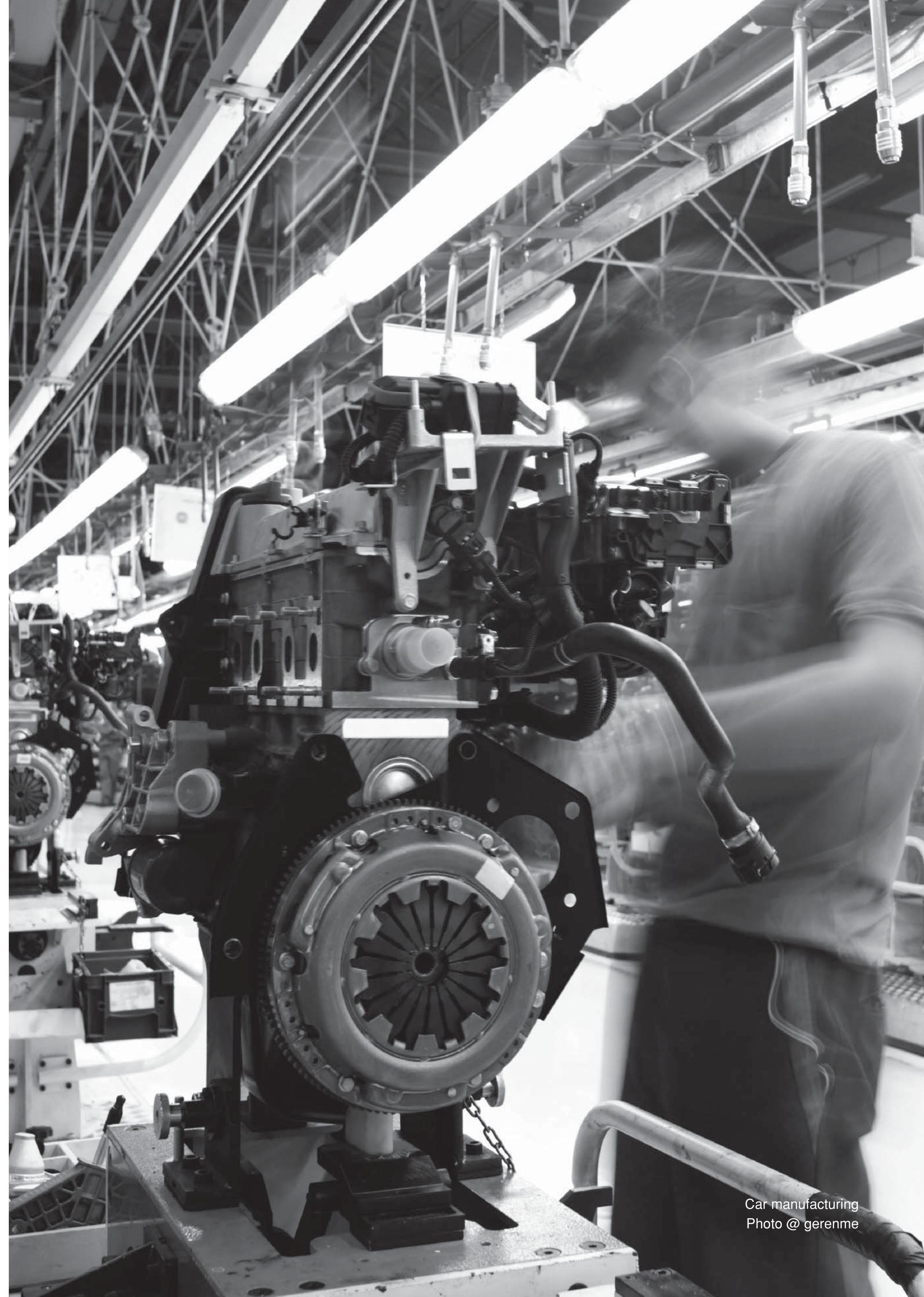




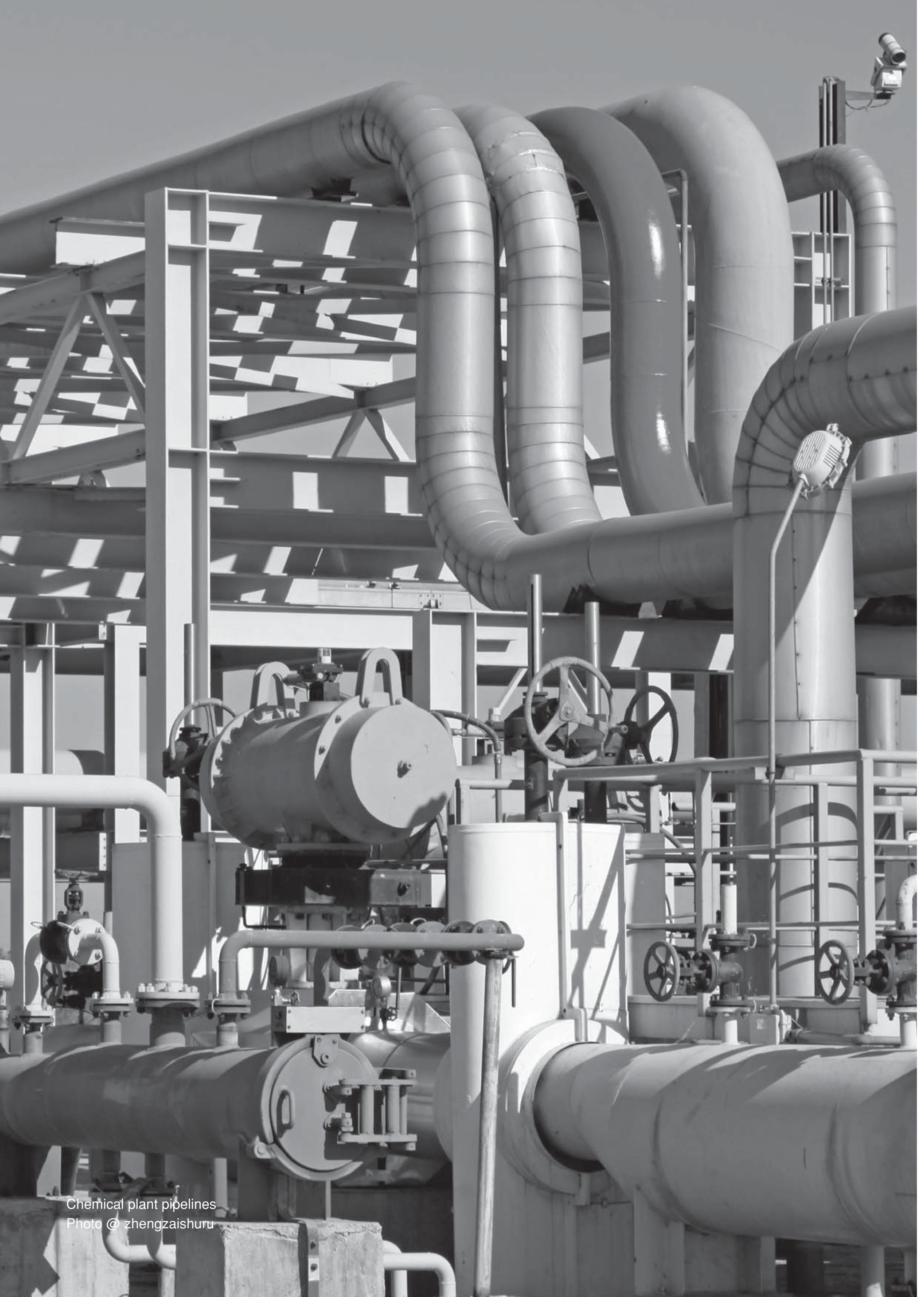

2

Drivers for EIP Development and Growth

The main drivers for eco-industrial parks (EIPS) remain grounded in business competitiveness. They also provide a platform for mitigating climate change through collective actions and innovation. These drivers include a desire for emission reduction on the national level; improved resource management due to increased resource costs and exposure to risks; environmental and social concerns from consumers; and increased demand to improve efficiency and growth.

Figure 21

The Impacts of EIPs Go beyond the Zone Framework

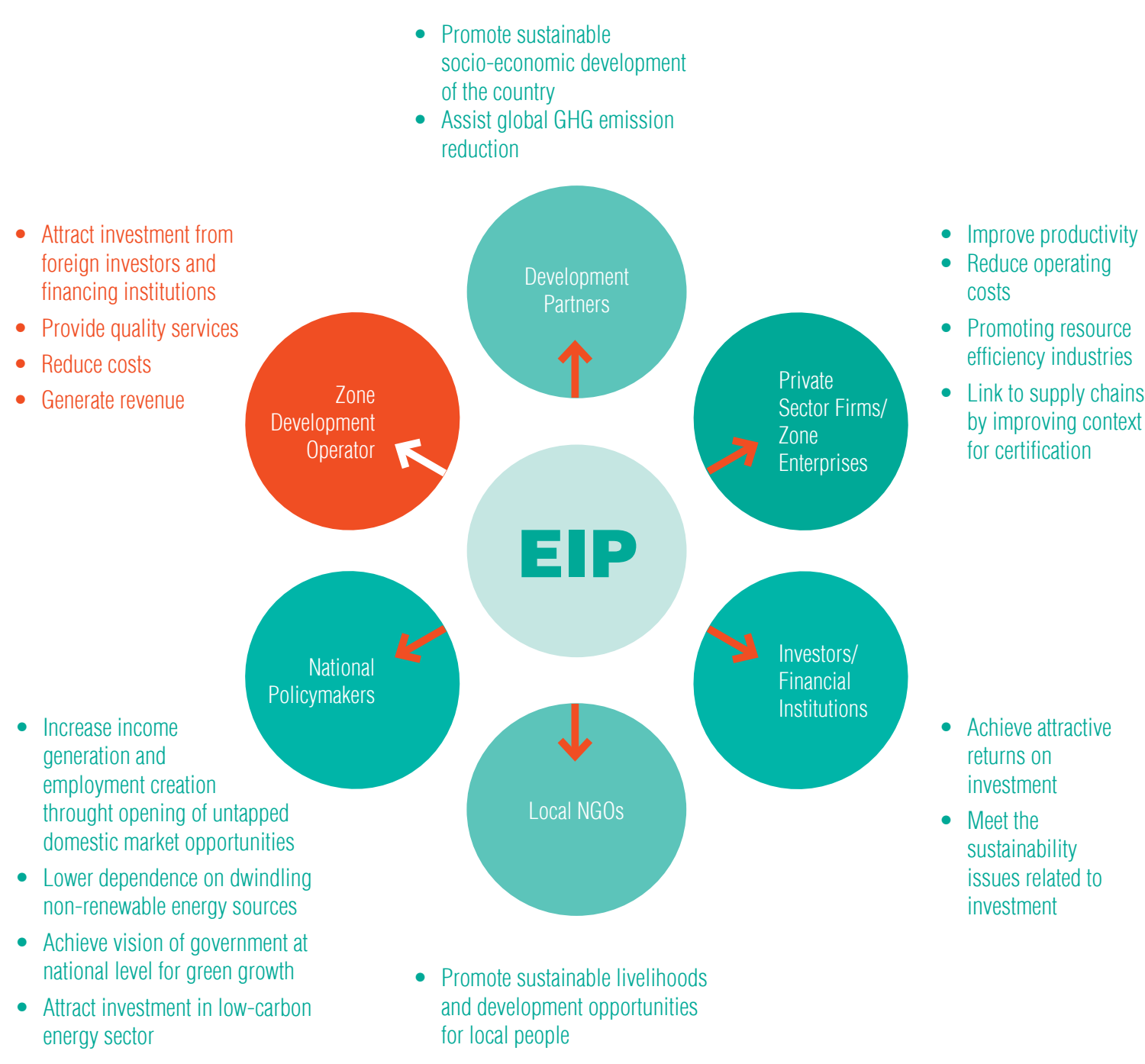


The benefits of the framework are multiple and reach across numerous stakeholders (Figure 2.1). The primary motivation of EIP developers and advocates, from World Bank experience, is the desire to provide additional services to investors and also serve as a plattorm to drive the sustainability agenda of a country. Also, Special Economic Zone (SEZ) authorities are conscious of the negative reputation that zones may receive, and the EIP framework allows them an added marketing opportunity. These factors can play an important role in driving countries to promote the EIP framework. There are numerous reasons why an industrial park would convert to an EIP, but fundamentally the current global drivers are the following:

\section{Mitigating climate change and energy security}

2. Greening the supply chain

3. Minimizing operating costs and improving productivity

Mitigating Climate Change and Energy Security

Climate change and the Paris Agreements have signaled a fundamental shift in how climate change is prioritized within the policy agenda of both developed and developing countries. The drive to finalize the agreements' National Determined Contributions, National Adaptation Programs of Action, National Appropriate Mitigation Actions, and related actions is making it important that industries play an active role in the climate actions of national governments and global supply chains.

Industries account for nearly one-third of the world's direct and indirect global greenhouse gas (GHG) emissions, and they will be playing an increasingly important role in achieving the global targets expected to be set at the international climate summit in Paris in December 2016. For example, the cement ( 5 percent), chemicals ( 7 percent), and iron and steel ( 7 percent) sectors account for nearly one-fifth of al global GHG emissions, and those sectors have significant potential to reduce those emissions.

EIPs can serve as a base in which firms manage their resource consumption through added services and the ability to create symbiosis between different entities. EIPs can also play an instrumental role in country efforts to achieve the targets set in the new Sustainable Development Goals (SDGs). ElPs can address a total of 10 targets under four different goals associated with clean energy, resource and energy efficiency and sustainable growth and industrialization.

\section{Box 2.1 EIPs and the Sustainable Development Goals}

\begin{tabular}{|c|c|}
\hline $\begin{array}{l}\text { The Sustainable Development Goals (SDGs) were } \\
\text { adopted in } 2015 \text { as a new, universal set of taraets }\end{array}$ & $\begin{array}{l}\text { Goal 7: } \\
\text { Ensure access to affordable, reliable, }\end{array}$ \\
\hline and indicators that United Nations member states are & $\begin{array}{l}\text { Ensure access to affordable, reliable, } \\
\text { sustainable, and modern energy for all }\end{array}$ \\
\hline $\begin{array}{l}\text { expected to use to frame their agendas and political } \\
\text { policies by 2030. Industries have an active role to play, }\end{array}$ & $\begin{array}{l}7.1 \text { By 2030, ensure universal access to affordable, } \\
\text { reliable, and modern energy services }\end{array}$ \\
\hline $\begin{array}{l}\text { primarily under goal 9: "Build resilient infrastructure, } \\
\text { promote inclusive and sustainable industrialization and }\end{array}$ & $\begin{array}{l}7.2 \text { By 2030, increase substantially the share of } \\
\text { renewable energy in the global energy mix }\end{array}$ \\
\hline foster innovation." & $\begin{array}{l}\text { 7.3 By 2030, double the global rate of improvement in } \\
\text { energy efficiency }\end{array}$ \\
\hline EIPs can serve as a catalyst to not only goal 9 but also & Goal 8: \\
\hline other aspects of the SDGs. & $\begin{array}{l}\text { Promote sustained, inclusive, and sustainable } \\
\text { economic growth, full and productive } \\
\text { employment, and decent work for all }\end{array}$ \\
\hline & $\begin{array}{l}\text { 8.1 Sustain per capita economic growth in accordance } \\
\text { with national circumstances and, in particular, }\end{array}$ \\
\hline
\end{tabular}

at least 7 percent gross domestic product growth per annum in the least developed countries

8.4 Improve progressively, through 2030, global resource efficiency in consumption and production and endeavor to decouple economic growth from environmental degradation, in accordance with the 10-year framework of programs on sustainable consumption and production, with developed

Goal 9 :

Build resilient infrastructure, promote inclusive and sustainable industrialization and foster innovation

9.4 By 2030, upgrade infrastructure and retrofit industries to make them sustainable, with increased resource-use efficiency and greater adoption of clean and environmentally sound technologlos and ind all countries taking action in accordance with their Goal 12:

Ensure sustainable consumption and production patterns

12.1 Implement the 10-year framework of program on sustainable consumption and production, all countries taking action, with developed countries taking the lead, taking into account the development and capabilities of developing countries

12.4 By 2020, achieve the environmentally sound management of chemicals and all wastes throughout their life cycle, in accordance with agreed international frameworks, and significantly reduce their release to air, water, and soil in order to minimize their adverse impacts on human health and the environment

12.5 By 2030, substantially reduce waste generation through prevention, reduction, recycling, and reuse

12.6 Encourage companies, especially large and transnational companies, to adopt sustainable practices and to integrate sustainability information into their reporting cycle

The EIP concept helps achieve these SDGs by (i) optimizing sustainable energy through solar rooftops or biomass, (II) lowering the use of valuable resources and improving how they are disposed through

resource efficiency and cleaner production measures, (iii) promoting circularity and industrial symbiosis, an (iv) ensuring the development of resilient and green infrastructure.

There is a pronounced shift in climate discussions toward its effect on industry—-both positive and negative - and who will be the winners and losers in terms of relative competitiveness at the country, sector, and firm levels. Threats to competitiveness in industry include disruptions in trade and global value chains due to weather events, greater volatility of resource inputs, decreased efficiency or efficacy of established industrial practices, and new regulations or standards that favor certain sectors over others. However, there are also significant costs to doing nothing, as illustrated in Figure 2.2.

\section{Figure 2.2}

Total Economic Cost of Climate Change under the Business-as-Usual Scenario in 2050 in South Asia

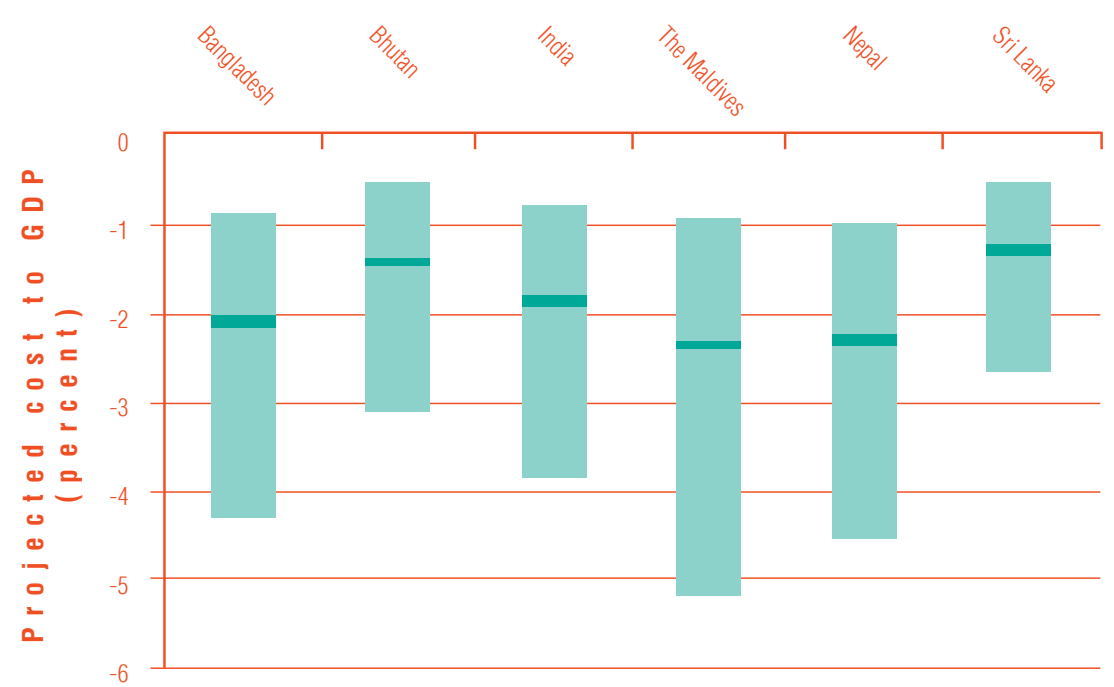




\section{Greening the Supply Chain}

The trend toward sustainable and climate friendly products has increased considerably in the past few decades. There is now considerable awroress that sustanabilty and climnate change actions along the supply chain are necessary in order to tackle climate change challenges. A recent report highlighted that 500 of the world's largest companies are responsible for more than 10 percent of the world's GHG emissions (Thomson Reuters 2014). The extent of their supply chains provides ample opportunities to increase sustainability.

Traditional supply chains have to adapt to the growing risks posed by climate change. Climate change affects the complexity of the existing supply chains mainly by impacting raw material avalability (like water and energy) or disrupting transportation capabilities. These incidents tend to have a profound effect by shifting irreversibly the global supply chain footprint of industries and taking operations out of

negatively impacted countries.

Figure 2.3

The Supply Chain Imperative

a. Sustainability factors

b. Key benefits

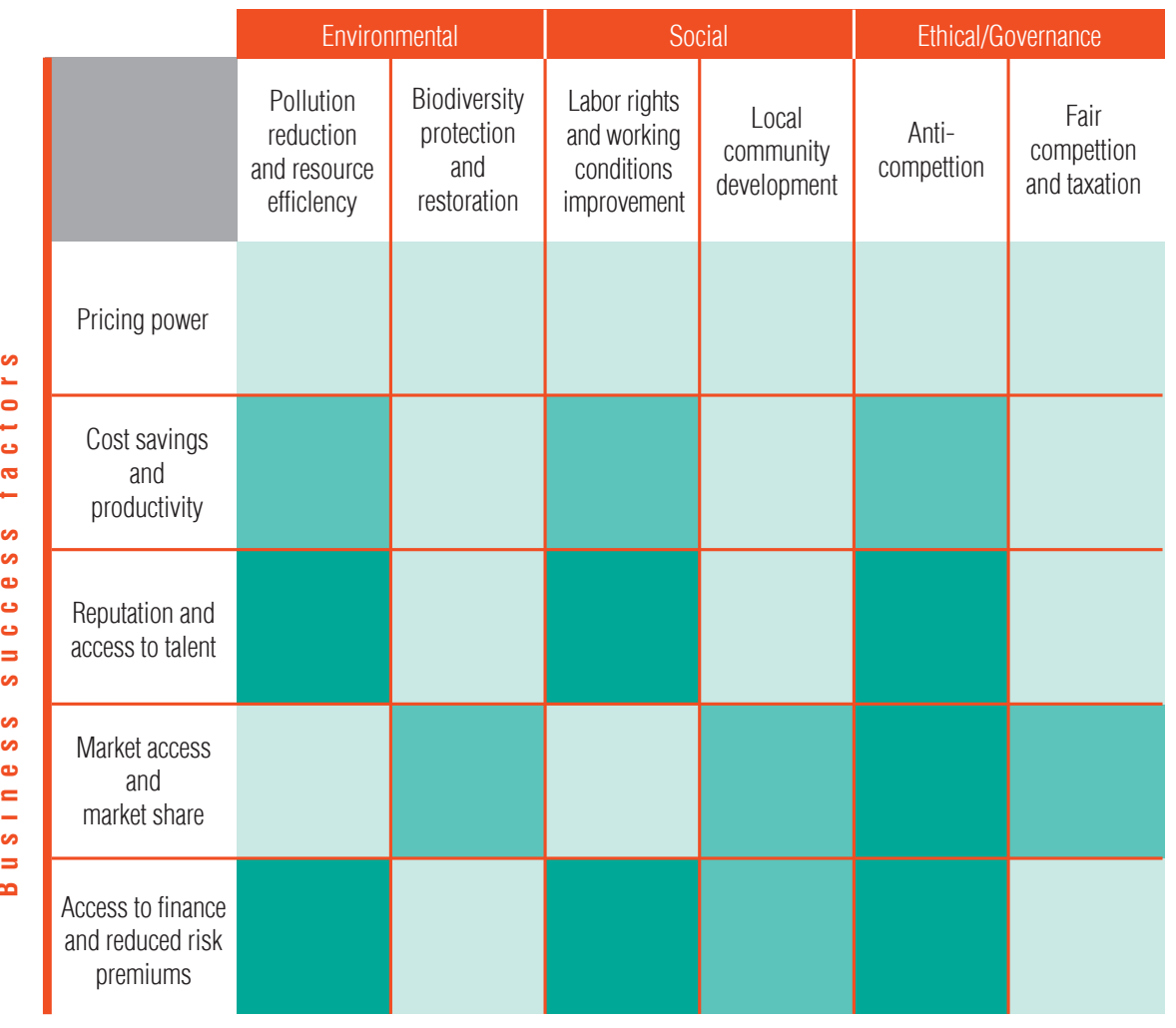

Lower operating costs - Resource efficiency, reduced
wastage lowers costs

Increase business continuily - Assure robust supply of highquality inputs - Decrease compliance-related supply disruptions

\section{Drive innovation and}

market share

Increase market access, drive

- Gain competitive advar

- Gain competitive advantage
over low-cost production

destinations

\section{Safeguard reputation}

- Garner less negative NGO and

\section{Atract investors and talen} (
Very high impact

- High impact

Impact

no impact
At the same time, this presents tremendous opportunities to client countries. Greening the supply chain is a strategic agenda for global companies sourcing from emerging economies (Figure 2.3). There will be an opportunity to make significant investments, mobilize public and private funding to address the needs, rapidly expand markets with no established players as yet, and benefit from profound and creative technological "disruption." This can allow countries to position their industries as new leaders in a very dynamic situation with associated benefits in jobs, investment, and development.

Companies are more conscious about the footprint of their supply chain and are taking positive actions with their partners and suppliers. A recent survey by Oxfam has shown that an increasing number of companies have taken actions in the area of climate change in the past few years (Oxfam 2016). See Figure 2.4.

Figure 2.4

Oxfam "Behind the Brand" Overall Score Change for Climate Change, 2013-16

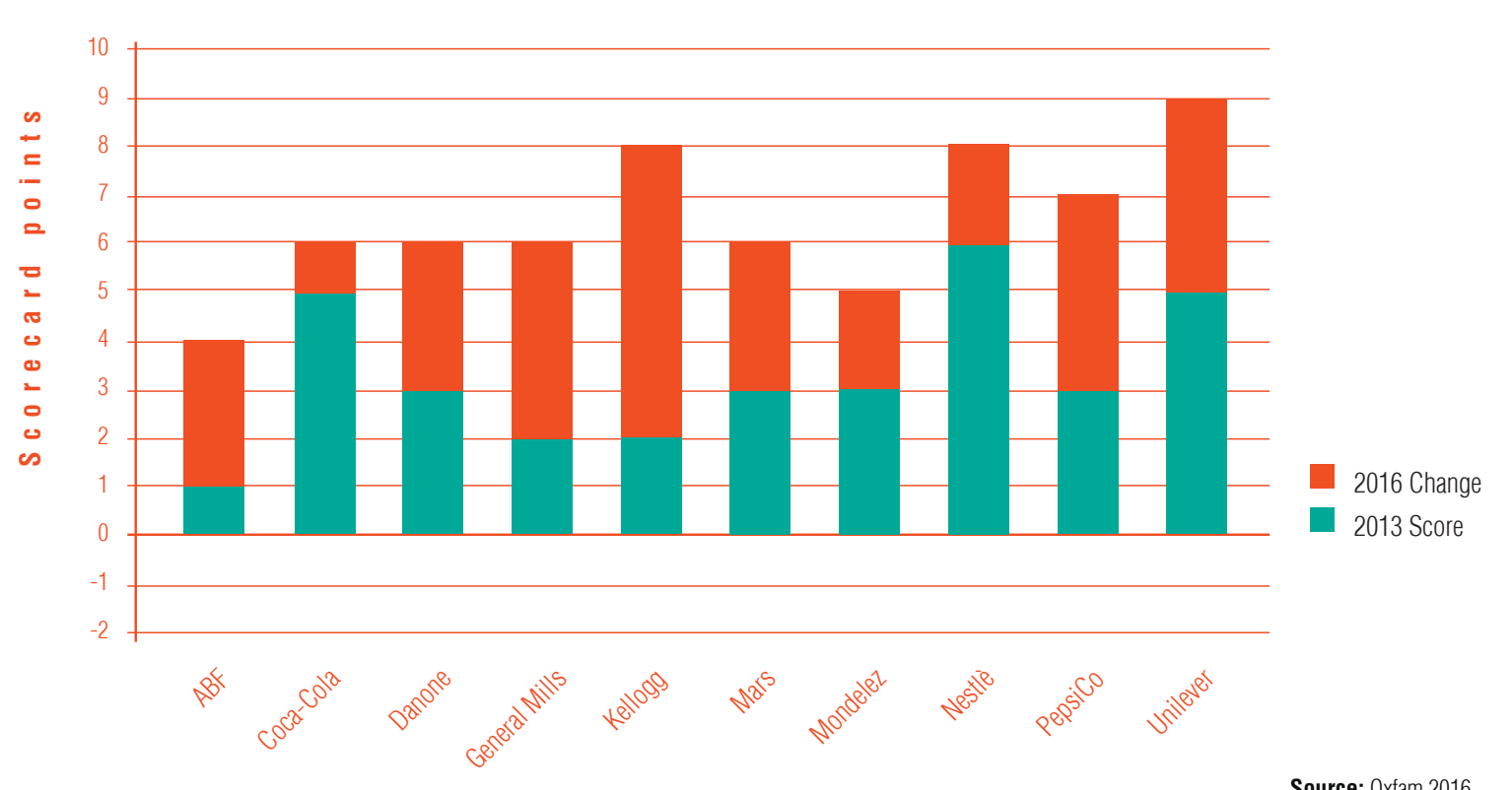

Source: : 0xam 2016

Unilever, Nestle, and Kellogg achieved Oxfam's highest scores across factors 7 categories, including climate change disclosure, deforestation and GHG emissions. Kellogg, in addition to including climate and sustainability targets in its supply chain, wants suppliers to disclose GHGs as part of an ambitious package of new environmental targets (Nichols 2014). Kerring, a top textile brand, has also set ambitious targets to lower emissions from its supply chain. The company found that it generates 12 percent of its total carbon emissions for its products, while the supply chain is responsible for the remaining 88 percent Coca-Cola aims to slash its emissions by one-fourth by 2020, the same year by which Unilever-one of the largest consumer goods companies in the world-aims to cut emissions in half.

The International Finance Corporation, the private sector lending arm of the World Bank Group, is working with partners and textile brands on improving sustainability across the textile supply chain in Bangladesh through its Partnership for Cleaner Textiles, a program funded by the Embassy of the Kingdom of the Netherlands in Dhaka and a group of international apparel buyers. This will help factories achieve cleaner production objectives by influencing product design and water and energy use in textile suppliers and 
improving stakeholder and government engagement in sustainability opportunities in the sector. Within three years the program has helped textile firms save over 13 million cubic meters of water while avoiding 170 thousand cubic meters of $\mathrm{CO}_{2}$ equivalent per year. ( $\mathrm{PaCT} 2016$ )

The role of EIPs in setting up a sustainable and climate-friendly platform for such supply chain actions Locating within an EIP, which effectively monitors and discloses its achievements, provides buyers an consumers a soft certification of a greener supply chain. As EIP is an added service to SEZ tenants, the operator of the zone can provide additional services in helping supply chain companies reach their sustainability targets.

Minimizing Operating Costs and Optimizing Resources

With a growing global population and peoples' increasing demand for a better quality of life, many resources are under pressure. This will increase prices and compromise availability. Industries face the danger of becoming less competitive due to increasing resource scarcity coupled with high and volatile energy costs, causing shocks in the market. To curb these impacts and ensure productivity of industries in a resource-scarce environment, governments need to scale up resource efficiency and cleaner production practices by promoting resource efficiency. And they need tools to enable them to prioritize practical energy- and water-saving opportunities for their key industries.

The Republic of Korea's shift toward more efficient production was due mostly to necessity caused by lack of indigenous energy sources and substantial increase in energy demand with high economic growth. The country ranks eighth in the world in energy consumption and ninth in oil consumption. In 2014, its cost of energy imports was US $\$ 1,741$ billion (33.1 percent of the total imports). In 2011, the total energy consumption of the nation's industrial sector was 126,886 thousand tons of oil equivalent (TOE), accounting for 61.6 percent of the total final energy consumption (205,863 thousand TOE). The nationa industrial complexes were responsible for 91,542 thousand TOE, equivalent to 72.1 percent of the industrial sector. Industrial complexes are responsible for 45 percent of total energy consumption

Figure 2.5

Proportion of Impacts from Different Costs on Chinese Manufacturing Firms

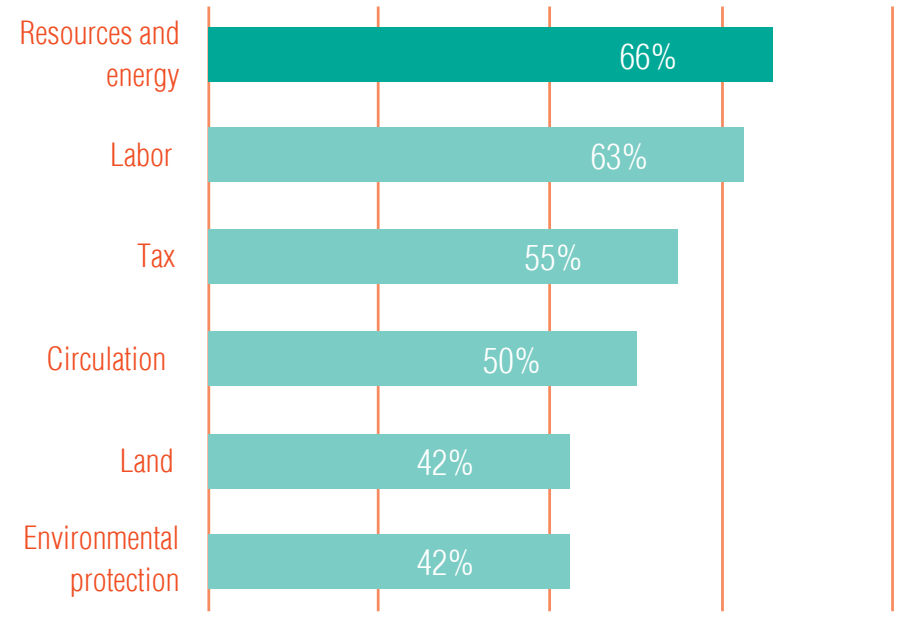

Private sector drivers can be seen from both a private zone operator and tenant perspective (Lee 2015).

Industrial competitiveness is being increasingly constrained not just by scarcity but also by price volatiity of resources like energy and water (Figure 2.5). Among climate change impacts, energy continues to remain the headline cost challenge for most industries globally, while declining water tables are raising concerns of sustained freshwater availability. These trends have placed increased emphasis on cost savings through resource efficient industrial operations.

- Input cost aside, the increased imperative for sustainable supply chains is compelling the emerging market industries to focus on resource efficiency and responsible social practices as a key differentiator from competition.

Deloitte's (2011) China Manufacturing Competitiveness Study illustrates that resources and energy costs Deloite's (201) Che have the higher also stes the the critical for the competitiveness of industries in developing countries.

More firms in the developing world are beginning to understand the impacts that resource and energy efficiency play in overall industrial competitiveness. Studies have shown that firms are motivated to incorporate more efficient green practices to reduce their costs and increase profitability. This business need is an even greater driver than government regulations. Not only does resource and energy efficiency provide businesses with the opportunity to reduce costs, more active management can turn waste streams into sources of revenue. Such active measures in management practice are being implemented in the eco-industrial parks of the Republic of Korea.

\section{Box 2.2 Cost Savings through EIPs}

From eco-towns in Japan to cogeneration in Bangladesh, governments and industries are reaping the benefits of resource efficiency. Japan's ecotowns combine resource efficiency with an integrated framework that benefits the community.

- Kawasaki Eco-Town, a resource recovery park, provides environmental services to the adjocent community through industry modernization. The resource recovery park is responsible for 69,000 esurce recovery park is rosponsible for 69,000 tpa r Ipa of plastics reused for form boards. In addition, synthesized nas production and and the use of synthesized gas production and alternative fuel have led to 0.5 million tons of waste diverted from land and US\$130 million annual economic benefit.a

- In China, the model of "circular economy system" has been adopted, especially in the iron-steel-metal products industrial ecosystem in China. This model has resulted in a 97.09 percent water reuse rate, 100 percent gas recovery rate, 100 percent iron dust utilization rate, 100 percent slag utilization rate, 100 ercent steel slag utilization rate, and 100 percent boiler fly ash (slag) utilization rate.

- Keumsung Commerce and Industry in the Republic or Korea saves about US $\$ 8,340$ per month in wastehandling costs and produces about US\$300,000 per month of total profit trom sale. By-products that have normally been part of the waste stream now contribute to revenue as the company is able to use the EIP etwork to sell its by-products. Participation in EIP efforts has helped to maintain a clean worksite that as reduced pest problems, and civil claims from the neighboring community due to foul odor.

- SCT, a Korean energy services company, is participating in an Energy Harmony Network, which it believes will result in sales turnover of US\$6.8 milli lemperature (120,000 gigacalories/yr) water supply. Expected sales turnover from selling electric power from ORC power generation is estimated to be US $\$ 4$. per year by selling the waste heat from medium- 
million per year. SCT expects to save US\$2.0 million per year in electricity costs and US\$2.6 million per year in residential heating costs by replacing the turbo refrigerator with an absorption refrigerator. Overall, the project expects the following outputs ${ }^{d}$.

$>$ Total investment cost $=$ US\$78.3 million; sales turnover = US\$11.6 million; energy savings =

US $\$ 4.6$ million per year

$>$ Reduction of $\mathrm{CO} 2$ by 26,693 tons per year, by

using waste heat decrease of $\mathrm{CO} 2$ by 10,335 tons per

year from the refrigerator change

- During a World Bank Group-supported project in Bangladesh, cogeneration of steam and electricity was identified as on of the most promising optity for $G$ G mitigation in the zost The Unitod Pone

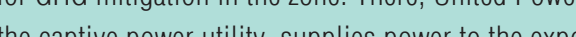
processing zone enterprises by running natural-gas-

fired generator sets. At present, the exhaust gas from The generator sets is vented into the atmosphere, but could alternatively be used to generate steam. Stean is a useful resource in the Chittagong EPZ that is widely used by the enterprises as part of their process operations. The process steam is presently generated separately at each individual enterprise, which may be replaced, partially or entirely, with the adoption of cogeneration by United Power.

a. Van Berkel, Rene. 2015. "EE0--Industrial Parks (EPP): Achivevements in and Lessons Learned from Developing Countries and Emerginn Economies. UNIDO. Presented a the Eco-Industrial Park 2015 Conterence

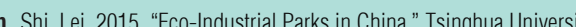

(

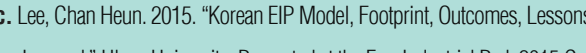

ter Co. Ltd. Presentedea at the Eco-Industrial Park 2015 Coniterence.
References

. Deloitte. 2011. China Marulacuring Competitiveness Study.

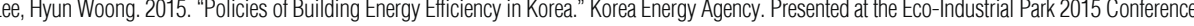

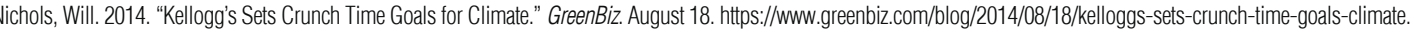

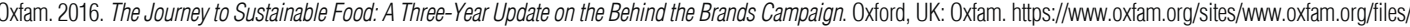

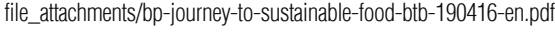

PaCT (Bangladesh Patrnership for Cleaner Textiles). htpp://mww.textilepact.ne/

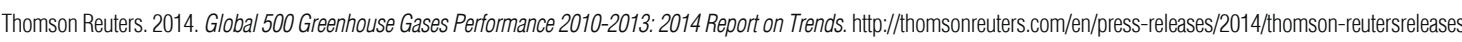
greenhouse-gas-emissions-data-on-global-500-companies.htm.

In addition to the noted direct impacts on the operations of firms, EIPs can also play a catalyzing role in driving the production of green and clean technologies by facilitating an ecosystem of innovation and promoting the development of cutting-edge technologies that can enable the low-carbon transformation

of industries elsewhere. The key benefits of "cleantech" industrials are as follows:

Clusters of companies bring disparate communities together: a network will bring investors, inventors, entrepreneurs and customers together to share insights and build mutual relationships.

- These clusters benefit from local assets and infrastructure: natural resources, local infrastructure, industry capabilities, local demand, research and development, and education are key local ingredients for accelerating the growth of a cleantech cluster.

- These clusters can facilitate gaps in funding, incubation, and commercialization: the presence of a cluster will often address perceived gaps in the development of any product or service by providing access to seed capital and incubation facilities. This is the phase that requires the most support when ideas are still being formed and not fully ready for the external market.

Green industries are increasingly being looked at as a new engine of industrial growth, with emerging focus on establishing cleantech clusters; there are dedicated cleantech clusters operating in Austria (Ecoworld Styria), Denmark (Copenhagen Cleantech), Finland (Lahti Cleantech), Canada (Ecotech Quebec), and the United States (Cleantech San Diego). These industrial clusters, while not being traditional $\mathrm{bec}$ ), and the United States (Cleantech San Diego). These industrial clusters, while not being traditiona
EIPs, have been instrumental in driving the supply of green and environmentally friendly technologies, products, and services and attracting and mobilizing investments from across the globe in pursuit of products, and services and attracting 


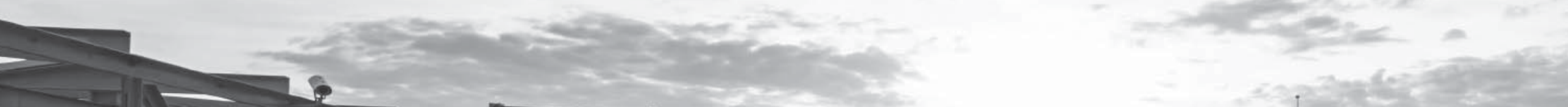

VAV in

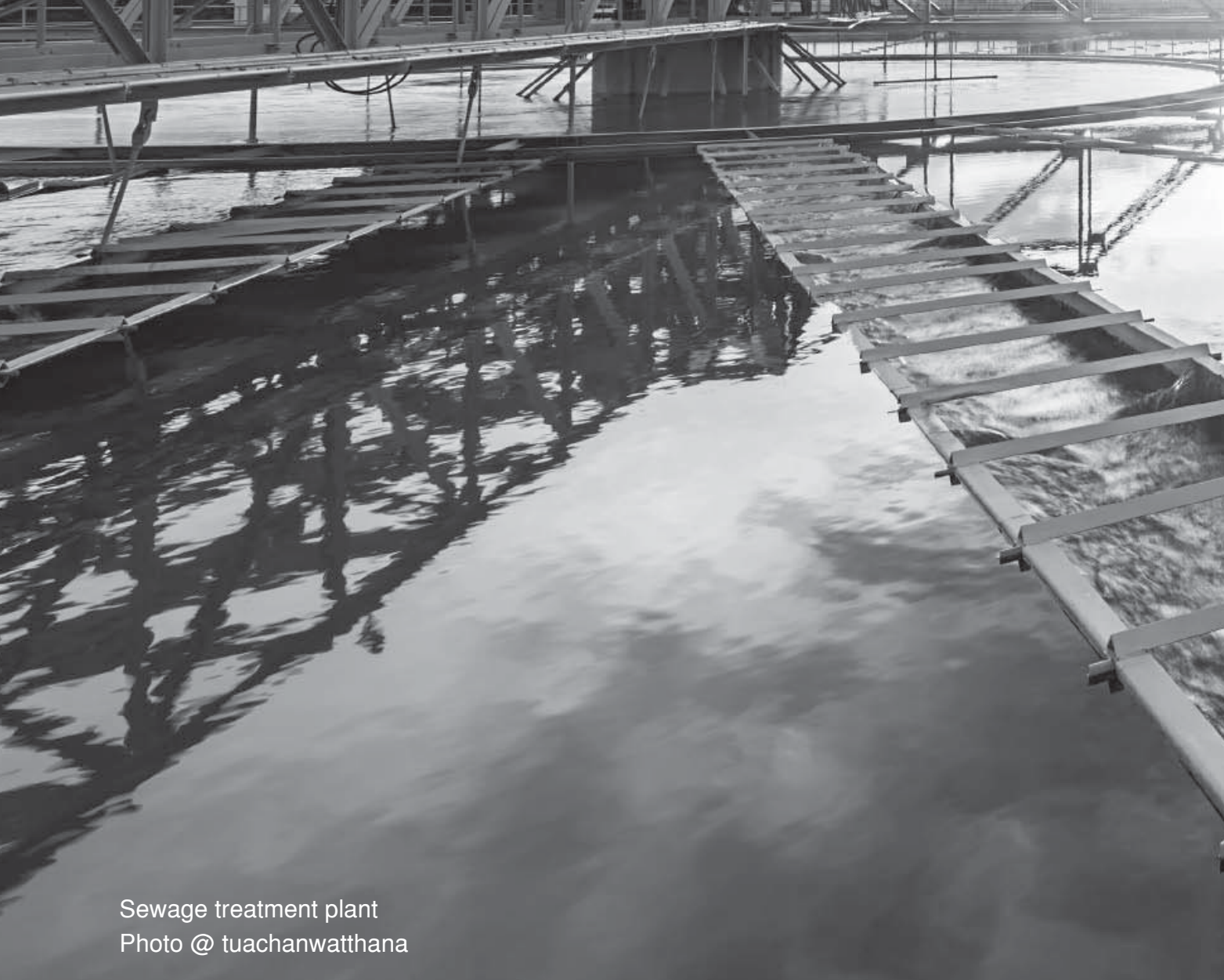

\section{$=$} cisom.

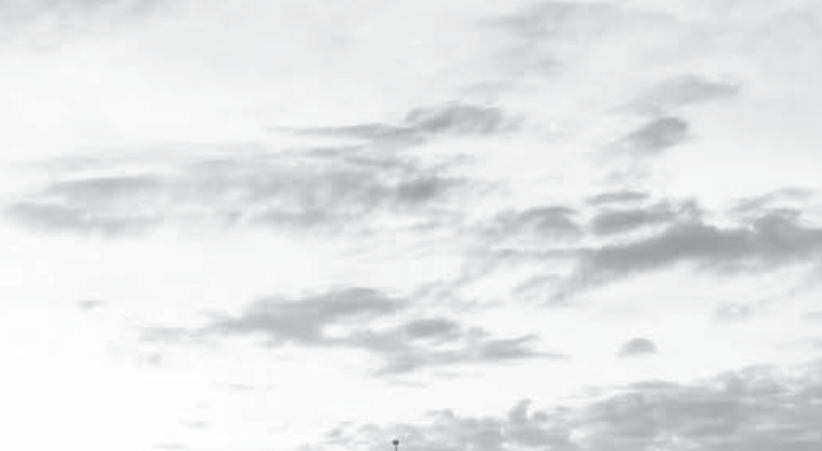 \\ -}

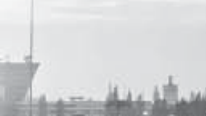

AW

se

A
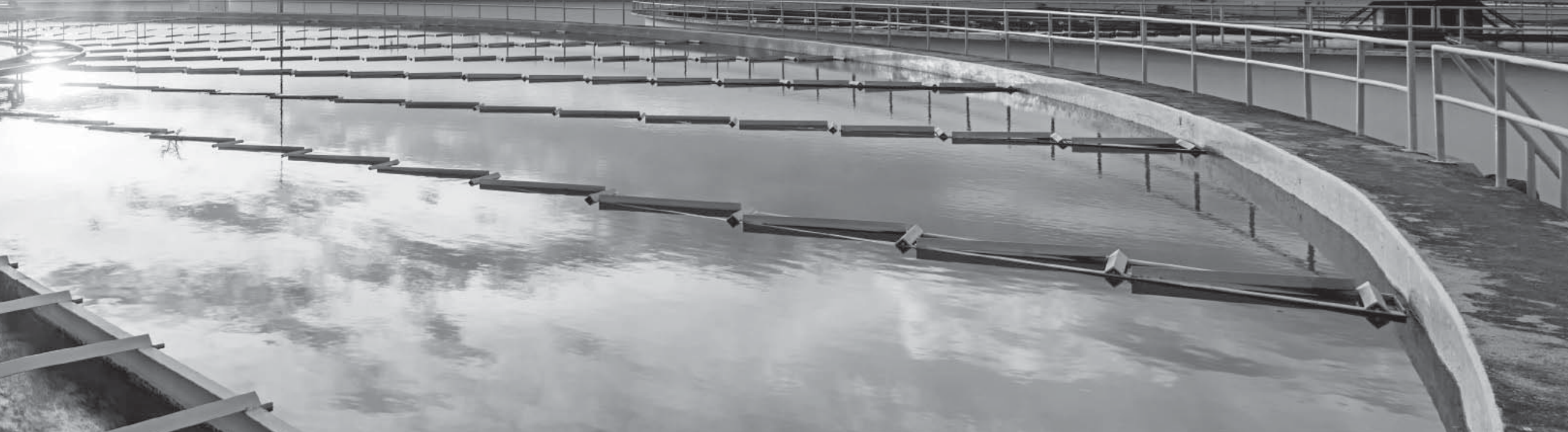

.

.

,

1. 


\section{Mainstreaming EIPs}

The global drivers are arguably in place to catalyze or mainstream the eco-industrial park (EIP) concept. At the more than 250 EIPs that have been identified through different sources, operators have taken various eco-friendly measures. Of the 212 EIPs that had information available, 50 percent had taken measures on waste management and energy efficiency measures; 45 percent enpl efficiency or cleaner production; and 35 percent used renewable energy and waste management
within their EIP framework. The majority had a mix of these factors in addition to others (Table 3.1).

Table 3.1

Number and Percentages of EIPs That Have Taken Selected Sustainable Measures

\begin{tabular}{|l|c|c|}
\hline Waste management & 109 & $51 \%$ \\
\hline Energy efficiency & 106 & $50 \%$ \\
\hline Industrial symbiosis & 95 & $45 \%$ \\
\hline Resource efficiency & 75 & $35 \%$ \\
\hline Renewable enegry & 74 & $35 \%$ \\
\hline Water management & 70 & $33 \%$ \\
\hline
\end{tabular}

The development of an EIP can take two forms: (i) an EIP can be embedded in the basic design of an industrial zone or (ii) an existing zone may be transformed into a resource efficient enclave. In either case, a systematic approach is necessary to identify and implement the technical opportunities targeted at optimizing resource usage and reducing waste and emissions. According to Deutsche Gesellschaft für Internationale Zusammenarbeit (GIZ), to embed eco-design at an early stage of an EIP, the Special Economic Zone (SEZ) developer needs to consider the following:

- Integration of the park in surrounding infrastructure

- Efficient land-use planning

- Planning of park infrastructure

- Energy supply

- Water supply, waste, and wastewater treatment facilities

- Environmental, emergency, and social facilities

This will simplify the SEZs incorporation of EIP concepts and save significant costs to the operator and tenants in the long term. In India, GIZ has developed an extensive EIP master planning project that helped convert a conventional master plan into one that incorporates ecological and social measures in its design and operational plans. The Green Industrial Park Jadcherla in the South Indian state of Telangana incorporated sustainability elements into road design and transport, green spaces, waste water treatment, energy networks, and an extensive list of technical requirements (GIZ and German Cooperation 2015).

In order to operate as an EIP, an industrial park should overperform compared to a conventional industria park on specific areas where the selected technical opportunities will pave the way for industrial green growth. As a baseline, it is assumed that the EIP has already adhered to national and international industrial good practices and has implemented policies that are conducive to EIP development. These practices may be direct regulations on EIP development, with clear guidelines and indicators, or a proactive policy toward eco-friendly development, such as promotion of renewable energy, policies and actions on energy efficiency adoption of national climate targets, and incentives that promote sustainable practices within industries (see Table 3.2)

Table 3.2

Areas of Policy Intervention to Support EIPs

\begin{tabular}{|c|c|c|}
\hline \multicolumn{3}{|c|}{ Policy framework } \\
\hline \multicolumn{3}{|c|}{ Policy framework governing energy performance } \\
\hline 1 & Electricity and other energy regulation & $\begin{array}{l}>\text { Overarching legal framework establishes the definition and pricing of energy and guides the } \\
\text { behavioirs of relevant authorities governing and participating in energy transactions }\end{array}$ \\
\hline 2 & $\begin{array}{l}\text { Energy efficiency law and associated } \\
\text { polices }\end{array}$ & $\begin{array}{l}\text { > Provides framework for implementing energy performance standards across the country, including } \\
\text { business enterprises within SEZs } \\
\text { > Estanlishes the governing authority and setting standards for different categories of energy } \\
\text { consumers }\end{array}$ \\
\hline 3 & $\begin{array}{l}\text { Minimum energy performance } \\
\text { standards }\end{array}$ & $\begin{array}{l}>\text { Generally implemented in conjinnction with energy labeling program } \\
>\text { > Guides or mandates energy consumers to move toward a more energy efficieient future }\end{array}$ \\
\hline 4 & Energy audit & $\begin{array}{l}\text { > Representst the basic first step toward energy management } \\
\text { > Sets forth energy audit processes } \\
\text { > Certifies energy auditiors } \\
\text { > May mandate periodic energy audits a t select or all business enterprises }\end{array}$ \\
\hline 5 & Standards and labeling & 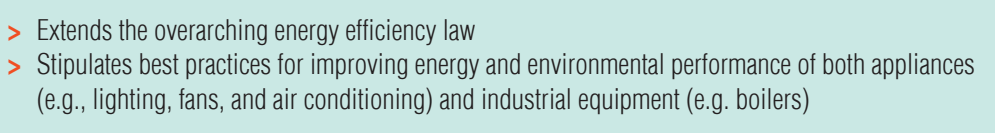 \\
\hline \multicolumn{3}{|c|}{ Policy framework governing environmental performance } \\
\hline 1 & $\begin{array}{l}\text { National pledges for GHG emission } \\
\text { reduction }\end{array}$ & $\begin{array}{l}\text { > Can be voluntary or mandatory } \\
\text { > Representis the minimum emission reduction standards for all business entererrises within the } \\
\text { country }\end{array}$ \\
\hline 2 & $\begin{array}{l}\text { National environmental law and } \\
\text { associated policies }\end{array}$ & $\begin{array}{l}\text { > Sets the standards for management and discharge of waste, water, and other effluent from } \\
\text { business enterprises }\end{array}$ \\
\hline \multicolumn{3}{|c|}{ Policy framework governing energy pricing } \\
\hline 1 & Energy and resource tariff regulations & $\begin{array}{l}\text { > Sets the taritif computation mechanism for energy and other resource transsactions } \\
\text { > Allocates subsidides to select resources } \\
\text { > Introduces incentive mechanisms like feed-in-tarifits for renewable energy }\end{array}$ \\
\hline 2 & Incentives and budgetary support & $\begin{array}{l}\text { > Allocates capital subsidies or grants toward "promoted" industries or initiatives to improve } \\
\text { competitiveness and overcome market failures }\end{array}$ \\
\hline
\end{tabular}

Source: Modified from Yeo and Kechichian 2014 
These policy measures are well documented as good practices for energy and climate policy for industry. EIPS will optimize their performance if the general policy framework of the country is supportive of cleaner production, renewable energy and other eco-friendly measures and investments in cleaner technologies. Some of the most proven, doable, cost-effective, and scalable technical opportunities are highlighted in Figure 3.1.

Figure 3.1

Areas of Policy Intervention to Support EIPs

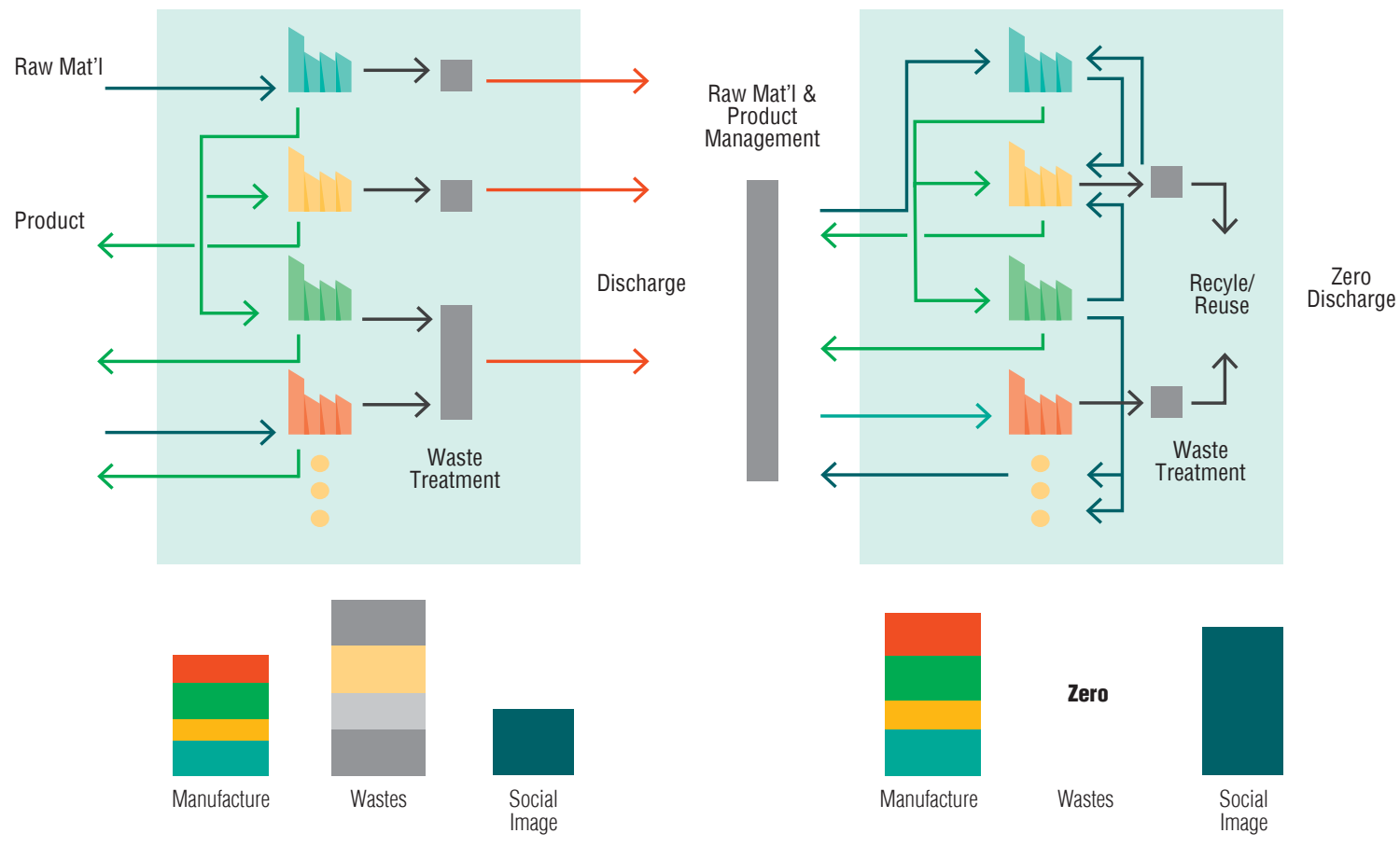

Present Industrial Park
Green Infrastructure and Clean Energy

The core offering of an SEZ to its tenants under the Zone 3.0 model is an enhanced and integrated service encased primarily in the industrial park infrastructure, with the main trigger for EIP being energy. Provision, distribution, and recovery of energy is the main area where the developer and operator have leverage with which to ensure a greener infrastructure.

In an ideal case, the energy for an EIP would come primarily from renewable sources. The energy supply from renewables in terms of both the energy mix and captive power is a core element of EIPs. To differentiate itself from conventional industrial parks, it is crucial that an EIP have a cleaner energy infrastructure than the average national energy mix Grid energy tends to be the main source of power for industrial parks Therefore, the grid emission factor (GEF) will play an important role in determining whether an industrial park can be considered an EIP. GEF is commonly expressed in tons of carbon dioxide equivalent per megawatt hour electricity ( $+\mathrm{CO}_{2}$ sustainability in its energy supply mix.

Clean energy sources are increasingly reaching price parity with conventional grid power, following significant reductions in capital expenditure. (See examples of cost-effective green energy options in box 3.1.) This has made renewables, and particularly solar, a highly lucrative option for replacement of conventional fuels for electricity generation. Industries are increasingly adopting options like rooftop solar to cut down on grid power usage. Zone authorities may also look at renewables-based microgrid infrastructu to supply power to zone tenants. While power demand is unlikely to be met from renewables entirely, innovative arrangements may be made to shift peak load power to renewables-based generation capacity.

The main concept of green infrastructure relies on the idea of bringing a common service into usage for the enterprises within a zone in a climate-friendly, resource and energy efficient manner so as to add a positive value on greening the zone. Typically, green infrastructure should be planned right from the conceptualization and design of EIPs. It also represents an easy target when transforming an existing zone into a greener enclave. At the zone level, common effluent treatment plants and street lighting are the most widely used green infrastructure interventions. Low-carbon transformation of street lighting, in particular, can be achieved either through installation of solar-driven lights or use of efficient fixtures such light-emitting diode (LED) lamps. At the firm level, green infrastructure refers to systems that are more climate-friendly compared to conventional ones in terms of resource utilization, electricity consumption, water efficiency, and so forth. Investors and zone operators may look at green factory and green building certifications as a potential modality for green transformation of the realty infrastructure within the zone.

EIP projects also need well-designed alternative financing sources to overcome the financial bottlenecks stemming from political and economic instability, local banking structures, limited liquidity, and lack of capacity or experience. In order to stimulate industrial players' interest in EIP development investments or transformation of existing industrial parks into EIPs, public-private partnerships (PPPs), fiscal incentives, local financing, or a combination of them have been used. Innovations on tailored financing mechanisms are needed for EIP projects so they can more easily be brought to financial markets.

The section below will provide brief insight into the key elements of EIP operations. They are drawn from lessons learned in existing EIP projects but are not, at this point, conclusive.

\section{Box 3.1 Savings from Green Industrial Infrastructure}

Clean energy solutions will result in operational cost savings and GHG reductions, and as a spillover impact they will lead to cleaner production by avoiding air

emissions that most conventional power plants cause. As the grid emission factor varies from country to country, the estimated GHG reduction will be location dependent. For instance, generation of 1 gigawatt hour of electricity from a renewable source in Turkey will enable a reduction of approximately 600 tons of $\mathrm{CO}_{2}$-equivalent $\mathrm{GHG}$ by replacing the electricity from the national grid. The replacement of conventional resources with renewable ones will also delete or decrease fuel costs (for coal, natural gas, fuel oil, and so forth). In addition, renewable energy solutions can be implemented on a small scale, onsite in EIPS, without the need for costly improvements to the national grid. As such, planned industrial zones panels in zones as a key energy source.

A recent World Bank project in Bangladesh aimed to develop a roadmap for low carbon growth and design optimal policy framework to facilitate it for Chittagong Export Processing Zone (CEPZ). A two-phase approach was followed, as detailed in figure B3.1.1. in many countries like Jordan or India incorporate sola 


\begin{tabular}{|c|c|c|c|}
\hline \multicolumn{4}{|c|}{$\begin{array}{l}\text { Figure B3.1.1 } \\
\text { Roadmap for Low Carbon Growth for Chittagong Export Processing Zone } \\
\text { Low carbon growth potential for CEPZ and design an optimal policy framework to facilitate }\end{array}$} \\
\hline \multicolumn{4}{|c|}{ Preparatory diagnosics: Study of GHG inventorization report by KICOX } \\
\hline \multicolumn{4}{|c|}{1 Low Carbon Green CEPZ Technical Diagnostic } \\
\hline \multirow[t]{2}{*}{ 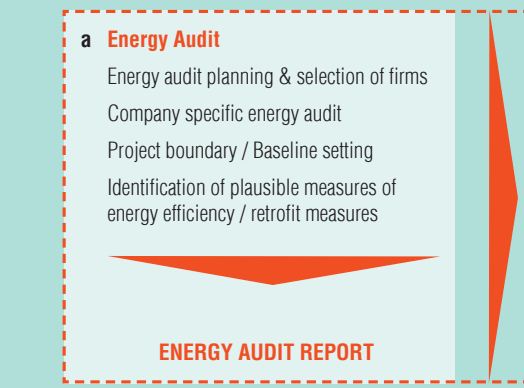 } & \multirow{2}{*}{\multicolumn{2}{|c|}{ 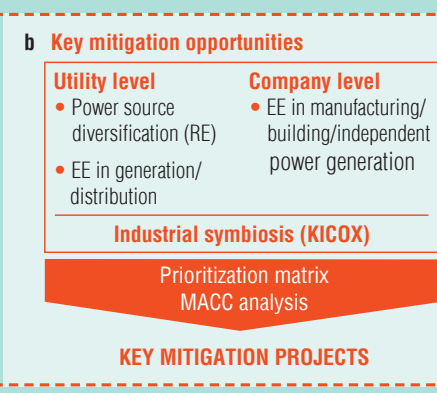 }} & \multirow{2}{*}{ 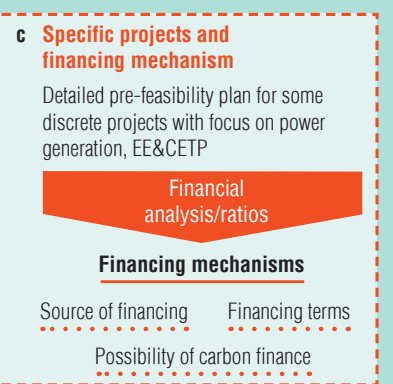 } \\
\hline & & & \\
\hline \multicolumn{4}{|c|}{2 Regulatory Framework and Implementation Support } \\
\hline 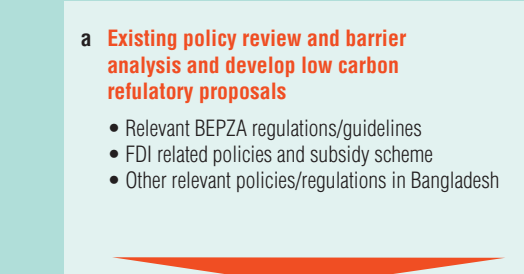 & \multicolumn{2}{|c|}{ 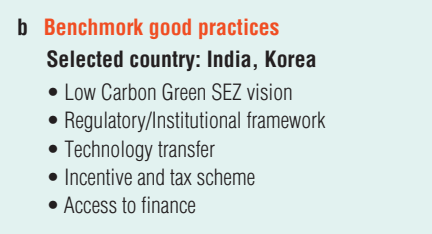 } & \multirow{2}{*}{ 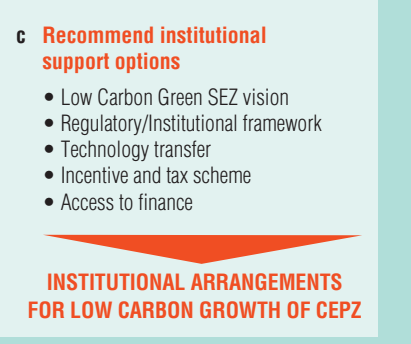 } \\
\hline KEY BARRIIERS/POSSIBLE SOLUTIONS & & & \\
\hline \multicolumn{4}{|c|}{3 Roadmap for Low-Carbon Green CEPZ } \\
\hline \multicolumn{2}{|c|}{$\begin{array}{l}\text { As a technical intervention, } 785 \text { electric poles with } \\
\text { solar panels have been installed to provide eco- } \\
\text { friendly lighting at the CEPZ. A yearly } 244 \mathrm{CCO}_{2}-\mathrm{e} \\
\text { GHG reduction and } 331 \text { megawatt-equivalent energy } \\
\text { consumption avoidance is expected as an outcome of } \\
\text { this project. The impact of green factories or buildings } \\
\text { is far more holistic, leading to multiple benefits } \\
\text { in terms of energy and water consumption saved, } \\
\text { emissions avoided, and reduced waste. In 2011, an } \\
\text { efficiency survey found that compared with a typical }\end{array}$} & \multicolumn{2}{|c|}{ 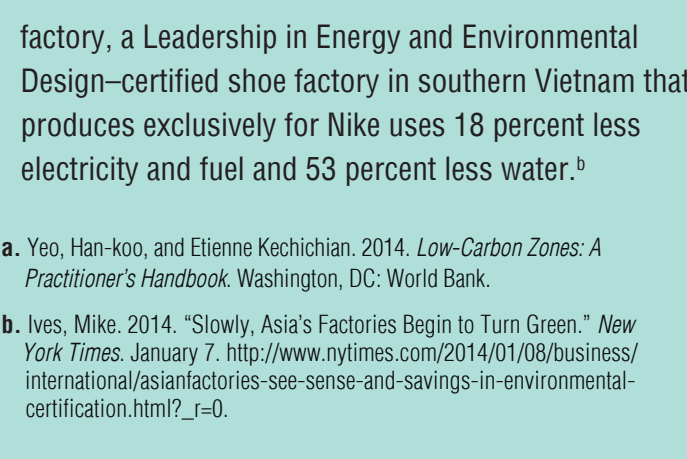 } \\
\hline
\end{tabular}

\section{Main Factors of Success}

The success of clean energy solutions at both EIP and firm levels depends heavily on the choice of technology and the associated cost of installation, operation, and maintenance. The existing price of power also plays a critical role: heavily subsidized conventional power greatly limits the returns from substituting renewable capacity. Renewable energy projects also benefit from carbon markets for climate change mitigation activities once a carbon market mechanism is introduced. At the country level, renewable energy projects are a great contribution to country-level emission reduction targets, especially where Kyoto Protocol is ratified.

Green infrastructure changes made in the transition of an industrial zone into an EIP have a greater impact than interventions by individual firms may have. They also enhance the quality of common utility infrastructure provided to tenant firms, which can also enhance their productivity.
Common Financing Opportunities

Generally speaking, PPPs are an option for government infrastructure investments where the government falls short of expertise and would like to tap into the private sector's experience. In a similar manner, PPP appears to be an option for financing EIP investments. PPPs are coupled with new solutions and finance opportunities. The public sector can drive the technical and qualitative efforts in collaboration with zone authorities. This results in a reduction of transaction costs. Such PPP arrangements between the public and private sectors are viable where shared investments brings mutual benefits.

As noted in box 3.1, the authority for the Bangladesh Chittagong EPZ, the zone authority was in need of financing for a street-lighting system, one of its more energy-intensive infrastructure projects. The investment was realized through a PPP model for the installation of 785 electric poles with solar panels for street lighting. As a result of this project the Chittagong EPZ authority expects to save around US $\$ 25,500$ electricity cost per . $\mathrm{CO}_{2}-\mathrm{e} \mathrm{GHG}$ emissions abatement annually as well.

In 2010, the Gujarat government in India had structured a PPP model to promote the implementation of solar rooftop photovoltaic projects. The model aimed to leverage the project developers' and intermediaries' position across the value chain of rooftop solar development in an emerging market. The project attracted approximately US $\$ 9$ million in private financing and added an additional $5 \mathrm{MW}$ capacity to power generation which resulted in access to power for 10,000 people and avoidance of 7 million cubic meter tons of GHG a year. The operators took responsibility for installation of panels and electricity transmission to the grid. In tum they would receive a feed-in tariff (FIT) (World Bank 2015). The structure is expressed in Figure 3.2.

Figure 3.2

Structure of the Gujarat Rooftop Solar PPP

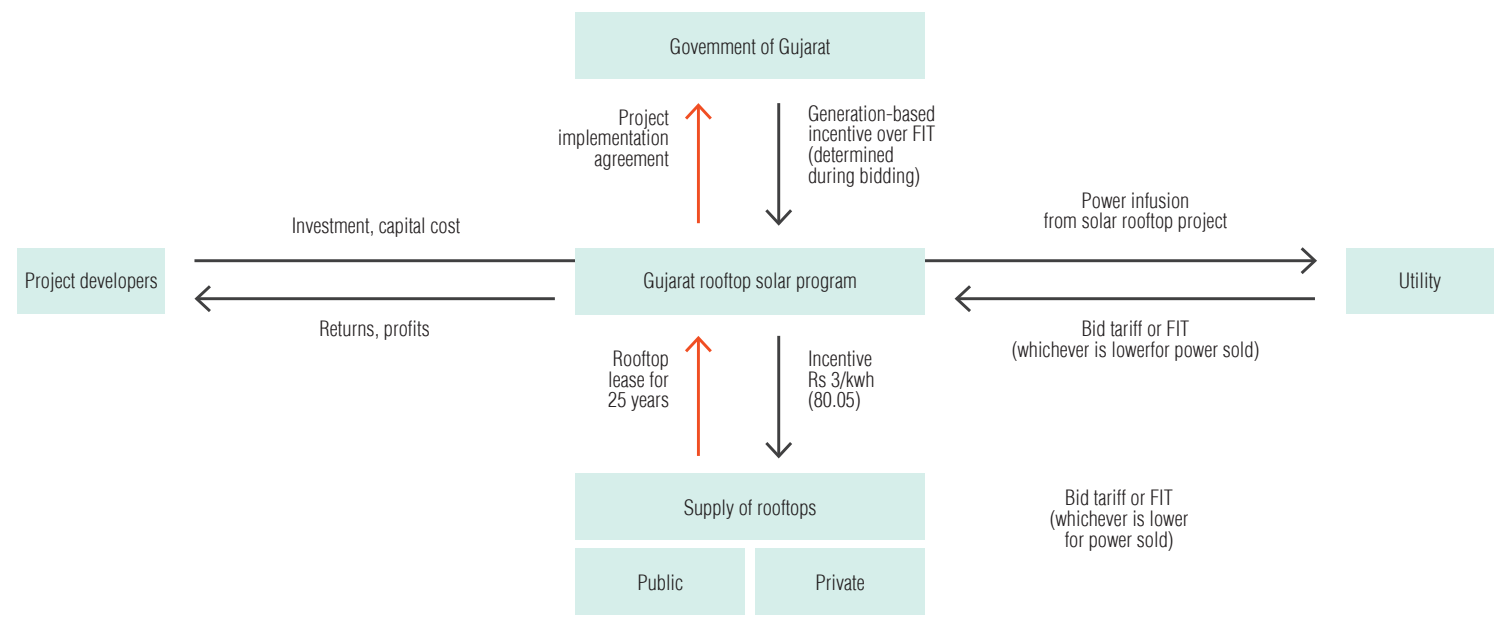

Source: Sinha and Sethi 2015

In an ordinary public project, capital cost and public profit are the points in question, while in the PPP model, the capital cost (investment cost and financing expense of private company), public guarantee risk ratio, and PPP profit are the issues. As can be seen, instead of laying the burden on one party, within PPPs the risk is shared among public sector and private sector participants. PPPs are ideal for long-term investments such as infrastructure. 
In some cases of EIP financing, international financial institutions provide public funds to be used for public investments. Such financial support generally flows into related government counterparts' deposits as international funds or grants. When the government counterpart would like to compensate the private sector for its public infrastructure investments, a PPP becomes an ineviTable financing option to finance EIP investments.

A private finance initiative (PFI) appears to be an important PPP model providing cost-effective solutions. It is in use in numerous European countries such as France, United Kingdom, Italy, and Spain. Within this model the public sector shifts from being the operator and owner of public assets to being the buyer who purchases, through a predetermined contract, the project from the private sector participant(s)

Since industrial parks are condensed industrial areas, there are common green infrastructure solutions, and either large or small capital expenditures could benefit a large portion of a park's firms. Such projects include common effluent treatment plants, water treatment plants, and solar rooftops, and these could be accomplished by tapping into PPPs.

\section{Resource Efficiency and Cleaner Production}

In order to align with the EIP concept, the zone, as well as the residing tenants, should implement resource efficiency and cleaner production (RECP) measures within their operations. These would include (i) firm-level management standards that support the EIP concept, (ii) promotions by zone management to tenants encouraging them to adopt internal environmental and energy management systems, and (iii) adoption of RECP measures and standards by SEZ operators.

Internationally accepted standards, particularly the ones related to sustainability, environment, energy, and health and safety, could be a good proxy for firm-level RECP. As an alternative to the internationally accepted standards (for example, International Standards Organization and Occupational Health and Safety Assessment Series), if the firm has a dedicated department that deals with energy efficiency strategies and environmental management systems but is not certified yet under an authorized body, it could nonetheless add value to the eco-industrial concept through internal company efforts.

\section{Box 3.2 Examples of Savings from RECP}

\section{Firm-level interventions may consist of one project or a} mix of such projects as (1) retrofitting (ii) by-product utilization (for example, installation of a steam turbine to generate electricity from excess steam), (iii) in-house renewable energy system installation (for example, solar photovoltaic that feeds electricity only to the firm), (iv) replacing machinery or equipment new and more efficien ones, (v) replacement of fossil fuel dependence via refuse-
derived fuel usage, and (vi) water saving interventions (for derived fuel usage, and (V) water saving interventions (for example, storm-water collection systems and circulation).

Individual firms can benefit either by creating a new revenue source from what would previously have been discarded waste or by gaining cheaper access to source materials or energy from other firms. In the Plating and PCB (Plastic Circuit Board) Center at the Shiheun Smarthub in the Republic of Korea, a steam supply network distributes waste steam among 26 plating and PCB companies for a combined reduction of 6,680 MWh per year, operating and energy costs of 0.7 billion won per year (approximately US\$ 600,000 ), and creation of 0.5 billion won per year in income from selling waste hea (approximately US $\$ 430,000$.

At Chittagong EPZ, firm-level interventions were mapped out in phase 1a step by conducting a firm-level energy adit to identify plausible measures for energy efficiency and retrofit. For most projects, moderate savings and low payback periods were observed. For instance, a 250
KW compressed air system installation would need an

investment volume of US $\$ 13,000$, resulting a 352,000

The detailed firm-level interventions are shown

kWh yearly saving. For this investment, the payback was Table B3.2.1.

calculated as 0.6 years.

Table B3.2.1.

Prioritizing Resource Efficiency Opportunities for Firms in the Chittagong EPZ

\begin{tabular}{|c|c|c|c|c|c|c|}
\hline No. & Levers & Capex & Energy savings & Payback & Potential & Priority \\
\hline 1 & $\begin{array}{l}\text { Air optimization } \\
\text { in boiler }\end{array}$ & $\begin{array}{l}\text { US 2,500 for } \\
\text { an } 8 \text { TPH boiler }\end{array}$ & $\begin{array}{l}19 \mathrm{k} \mathrm{Nm}^{3} \text { for an } 8 \\
\text { TPH unit }\end{array}$ & 3.60 years & & $\begin{array}{l}\text { - Low savings } \\
\text { - Moderate payback } \\
\text { - No implementation challenge }\end{array}$ \\
\hline 2 & $\begin{array}{l}\text { Boiler FD fan RPM } \\
\text { optimization }\end{array}$ & $\begin{array}{l}\text { - US } 1,300 \\
\text { for } 4.5 \mathrm{~kW} \text { FD } \\
\text { fan motor }\end{array}$ & $\begin{array}{l}1571 \text { MWh } \\
\text { (considering 40-50 } \\
\text { boilers of capacity } \\
\text { 2-to-10 TPH) }\end{array}$ & $\sim 0.60$ years & & $\begin{array}{l}\text { - Moderate savings } \\
\text { - Low payback } \\
\text { - No implementation challenge }\end{array}$ \\
\hline 3 & $\begin{array}{l}\text { Compressed air } \\
\text { recycling system }\end{array}$ & $\begin{array}{l}\text { US 13,000 } \\
\text { for a 250 kW } \\
\text { Compressor }\end{array}$ & $\begin{array}{l}351,859 \mathrm{kWh} \text { for a } \\
\text { single compressor }\end{array}$ & $\sim 0.60$ years & & $\begin{array}{l}\text { - Moderate savings } \\
\text { - Low payback } \\
\text { - No implementation challenge }\end{array}$ \\
\hline 4 & $\begin{array}{l}\text { Steam condensate } \\
\text { recovery from } \\
\text { bleaching/dryer } \\
\text { units }\end{array}$ & $\begin{array}{l}\text { US 25,500 for } \\
\text { average } 8 \mathrm{TPH} \\
\text { boiler }\end{array}$ & $\begin{array}{l}0,15 \mathrm{milion}^{\mathrm{Nm}}{ }^{3} \text { of } \\
\text { NG for } 8 \mathrm{TPH}\end{array}$ & $\sim 2.20$ years & & $\begin{array}{l}\text { - High savings } \\
\text { - Low payback } \\
\text { - Condensate may be } \\
\text { contaminated }\end{array}$ \\
\hline 5 & $\begin{array}{l}\text { Heat insulation } \\
\text { panit for can-dryer }\end{array}$ & $\begin{array}{l}\text { US 4,000 for } \\
\text { painting }\end{array}$ & $\begin{array}{l}0,12 \text { milion } \mathrm{Nm}^{3} \\
\text { of NG for a unit }\end{array}$ & $\sim 1.30$ years & & $\begin{array}{l}\text { - High savings } \\
\text { - Moderate payback } \\
\text { - No implementation challenge }\end{array}$ \\
\hline 6 & $\begin{array}{l}\text { Energy savings } \\
\text { from steam-trap } \\
\text { management }\end{array}$ & $\begin{array}{l}\text { US } 54,000 \text { for } \\
\text { steam network } \\
\text { of } 18 \text { TPH }\end{array}$ & $\begin{array}{l}\sim 0,3 \text { milion } \mathrm{Nm}^{3} \text { of } \\
18 \mathrm{TPH}\end{array}$ & $\sim 2.30$ years & & $\begin{array}{l}\text { - Moderate savings } \\
\text { - Moderate payback } \\
\text { - Plant shutdown required }\end{array}$ \\
\hline 7 & $\begin{array}{l}\text { Waste-heat- } \\
\text { recovery type } \\
\text { pre-heater }\end{array}$ & $\begin{array}{l}\text { - US 2,500 for } \\
8 \mathrm{TPH}\end{array}$ & $\begin{array}{l}\sim 34 \mathrm{k} \mathrm{Nm}^{3} \text { for } 8 \\
\mathrm{TPH}\end{array}$ & 3.60 years & & $\begin{array}{l}\text { - Low savings } \\
\text { - Moderate payback } \\
\text { - Plant shutdown required }\end{array}$ \\
\hline 8 & $\begin{array}{l}\text { High-efficiency } \\
\text { inverter boiler }\end{array}$ & $\begin{array}{l}\text { US } 190,000 \\
\text { for a } 30 \text { TPH } \\
\text { boiler }\end{array}$ & $\begin{array}{l}\sim 0,6 \mathrm{milion} \mathrm{Nm}^{3} \\
\text { for } 30 \mathrm{TPH}\end{array}$ & $\sim 5.50$ years & & $\begin{array}{l}\text { - Very high payback } \\
\text { - Plant shutdown required }\end{array}$ \\
\hline 9 & $\begin{array}{l}\text { Introduction of } \\
\text { low-liquor ratio } \\
\text { dyeing system }\end{array}$ & $\begin{array}{l}\text { US 17,000 for } \\
\text { each dyeing unit }\end{array}$ & $\begin{array}{l}\text { 0,12 milion } \mathrm{Nm}^{3} \\
\text { for } 9 \text { dyeing units }\end{array}$ & $\sim 10.20$ years & & $\begin{array}{l}\text { - Very high payback } \\
\text { - Plant shutdown required }\end{array}$ \\
\hline \multicolumn{6}{|c|}{ 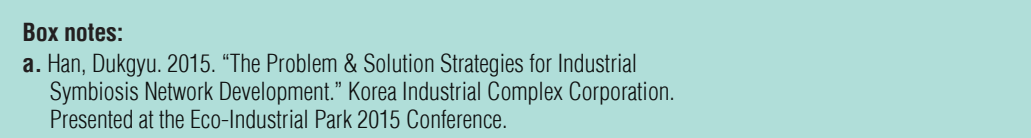 } & Source: Yeo and Kechichian 201 \\
\hline
\end{tabular}


Main Factors of RECP Success

A systematic approach should be adopted by both the firms in the zone and the zone operator to ensure successful implementation of the identified interventions. First and foremost, the firm should conduct a

detailed analysis of technical savings potential and how these savings will reflect on operational expenses and the required investment volume. This can be achieved by conducting an energy audit or walkthrough that would be followed by thorough technical feasibility diagnostics.

Availability of finance plays a crucial role in implementation of any technically feasible project. The firm should, therefore, also conduct a detailed financial feasibility analysis that will help establish not only project profitability but also sources of finance to mobilize implementation. Tailored credit lines, financin facilities, and grants that these projects fit into represent some of the key sources. Priority should be accorded in pursuing projects with lowest payback periods, thereby leading to quick wins.

Zonewide replicability of any viable intervention often depends heavily on the demonstration effect created by the first project. The zone operator, therefore, should participate, along with the firm in coordinating the relevant diagnostics and implementation processes of the first project. Thereafter, the operator should disseminate the learning through focused outreach activities and motivate other firms within the zone to pursue similar interventions. From a zone operator's perspective, this is an important added service the zone can offer to its tenants.

\section{Common Financing Opportunities}

A blend of direct finance and fiscal incentives are common financial solutions to bolster firm-level RECP interventions. In terms of commercial finance, specific financing facilities are alternatives to financing the projects in this group. Financing facilities framed for projects to increase energy savings and decrease carbon emissions can offer special terms to project developers. Evidence suggests that these kind of tailored finance facilities are able to offer better conditions compared to commercial finance in terms of borrower-friendly debt-to-equity ratio, lower interest rate, and longer period maturity. In addition, some local banks collaborate with international financial institutions by receiving credit lines from them and offering them to their clients for thematic projects. Most of the time, these credit lines offer borrower-friendly terms similar to those of financing facilities. These finance options facilitate small and medium enterprise commercial bank londing for RECP investments.

Performance-based fiscal incentives (PBIs) lessen the financial burden on project developers where the projects require procurement of new machinery and equipment for resource efficiency and cleaner production improvements. To benefit from fiscal incentives, the equipment performance should be easile measured as pat of the development proct. Equipment specifications should be tes Table to prove the expressed perfomance. Feed in tailis are a conmon type of PBls. For example the government of Egypt took a major step in July 2014 by signaling its commitment to reform and transform the energy sector, issuing a prime ministerial decree providing a roadmap for electricity tariffs in industries for the next five years, gradually increasing the tariff, and phasing out subsidies. Industries started seeking new ways to remain competitive that would reduce the risks posed by price increases. Standards and labelling of electrical motors could be one option offered by the government as a framework and tool to strengthen and accelerate energy efficiency programs and improve the market viability and attractiveness of industry innovations that address the new context.

Turkey, the Kayseri Organized Industrial Zone has been selected as a pilot project to shift from inefficient electrical motors to highly efficient ones within a financial aid program initiated by Ministry of Science, Industry and Technology. Loans of up to 300,000 Turkish liras (approximately US $\$ 100,000$ ) will be provided

to the industrial zone tenants who wish to upgrade their inefficient electrical motors. The loans will be provided with a 12-months grace period. The payback period is 36 months, with 3 - month interestfree equal installments every 3 months. For projects having a payback longer than two years, the fiscal incentives' monetary impact becomes more visible when the entire volume of the investment is considered.

\section{Fiscal Incentives}

Fiscal incentives are used as a supportive tool as part of governments' national strategy for energy efficiency and/or renewable energy projects. They are established to leverage investments of businesses for their transition in to a low-carbon future. They are aimed to scale up such investments by reducing fiscal impediments.

Countries often employ a mix of incentives to channel investment for development of a particular area or region, or to serve a set of governmental strategies for national prosperity. At times, industrial zones are linked to preferential fiscal regimes that help attract and retain certain types of investments. There are considerable arguments on the positives versus negatives of these regimes, although their continuous usage implies that the challenge is more in implementing a properly designed regime rather than whether they are the right tools or not. The fiscal regimes that the industrial zones are operating under can be harnessed to promote their transition into EIPs by targeting new investments into EIP development projects.

noteworthy form of fiscal incentives are PBis that area, such as renewable energy production or the energy-saving performance of industries. For example, for electricity production from solar utilization, typically incentives are paid based on the actual energy production of the solar system (dollars per kilowatt hour) over a period of time. PBIs lessen the financia burden on firm-level project developers, whose project requires procurement of new machinery and equipment that are more energy efficient than existing ones, or that enable electricity generation from renewables that can be used internally as a substitute to the grid, which is a mix of mostly fossil fuels.

As a general practice within SEZs and organized industrial zones, once procurement of equipment is in question for the renewal of equipment and/or switching to another system by means of equipment and machinery, the project sponsor may benefit from customs duty exemption and value-added tax (VAT) remission. For example in Turkey investors operating in the Organized Industrial Zones can benefit from for from real estate duty for five years starting after the construction of the plant.

\section{Box 3.3 Fiscal Incentives: An Example from South Africa}

Recently, South Africa made significant progress in the implementation of tax incentives in order to scale up energy efficiency investments and to facilitate green growth at the industrial level. Of course, South

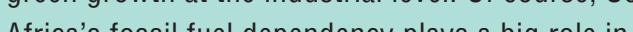
such tax strucher denency plays a big role in coal, which supplies around 70 percent of its primary energy and more than 90 percent of its electricity. In addition, within the past decade, electricity costs have increased by over 170 percent, while in other BRICS countries (Brazil, Russia, India, and China)

\section{the increase was 36 percent. Energy efficiency} investments gained importance in this environment. In order to scale up energy efficiency projects and south Africa, the government restructured its Income Tax Act. One of its articles states that taxpayers may get a deduction on firm income tax in the amount of 95 cents per each saved kWh over a particular incentive benefit period. This is a performance-based incentive based on energsaving performance and addressed to greenfield and brownfield manufacturing projects. ${ }^{b}$ One of 
the eligibility criteria for the projects is the use of improved energy efficiency and cleaner production technologies. The savings performance are gauged and verified by legitimate counterparts. In accordance with the new Income Tax Act, an additional allowance on assets (new or used) can be applied to energy efficiency or energy saving projects that qualify as an Industrial Policy Project after approval by the Minister of Trade and Industry. The top three sectors attracted by the program were chemical production (21 projects), cement and ceramics (7 projects), and the agroprocessing sector (3 projects), which represent approximity 80 percent of the total investments approved in the whole program.

In a nutshell, in order to scale up energy efficiency investments and to promote green growth at the zone level, governments can reshape their tax structures to foster industrial entities to invest in energy efficiency maximizing projects by means of shifting to more energy efficient technologies and other relevant projects. In order to implement a successful fiscal incentive regime, the potential

challenges that might stem from bad management of resource allocation, transparency, implementation processes, and monitoring should be tackled. For transparent and strong governance, the incentive's related information and its application, awarding, and granting process should be publically announced and made available and the tax incentives should be provided in the tax code. Aiming to avoid ineffective allocation of resources, the incentive authority should have a system in place to conduct regular and comprehensive assessment of the effectiveness of incentives. The incentives should not generate distortions that place some enterprises at a disadvantageous position in retation to others. In addition, while structuring the fiscal revime, close ad and cum and cum to no

Table B3.3.1 provides a succinct snapshot of the different relevant incentives in the context of climate efficient industrial development.

Table B3.3.1.

Incentives for Supporting EIPs

Financial $\quad$ Nonfinancial

- Reduced rents, utility surcharge on energy performance

- Capital subsidy for solar photovoltaic, central

- Goverment grant for demonstration projects

- Facilitating bulk procurement, for example of light-

Funds to provide seed capit

- Partial risk guarantee facility

Feed-in-tariff for grid connected renewable energo - Energy efficiency standards and labeling

- Energy efficiency concessional financing by banks

and financial institutions

effluent treatment plants, wasteto-energy
- Technical advisory support for energy audi - Donor-assisted capacity buildign suppor cognition scheme

ocused energy efficiency programs

- Rising enegry price; stricter environmental compliance

- Technical assistance for sector-based enegry audit, process improvement

- Award and recognition by industry chambers
Box notes:

a. Meier, P., Maria M. Vagliasinidi, and M. Imran. 2015. The Design and Energy Incentives: An Economic Analys Washington, DC: World Bank.

Greenfield projects are new industids projects are expansions or upgrades of existing industrial projects.

\section{Commercial Financing}

In some countries, such as Bangladesh and Turkey, the financial sector is dominated by local commercial banks. Project sponsors suffer when the local banks are unwilling to finance energy efficiency projects or show a lack of interest in offering tailored financial solutions. In Turkey it is a common practice of local banks to receive a credit line for energy efficiency related leases (replacement investments) or financing (new machinery and equipment investments) from international financial institutions and/or relevant green funds to offer project-specific financing solutions.

In addition to already mentioned financing options, EIP development projects can benefit from grants that are disbursed by local governmental agencies under certain terms. Most of them are structured so as to support national strategy and to guide improvement in a particular direction (for example, national energy efficiency strategic plan or national eco-town program). Looking at the amount of the disbursable grants per projects, it could be said that grants are not a panacea on their own for new development projects that must be built from scratch, but they could be a good option for retrofitting or for conducting feasibility studies to gauge potential for creating an EIP. In this sense, grants can be useful for supporting activities such as energy audits and studies on common infrastructure feasibility.

When there is a need of new machinery or equipment procurement for an EIP development project, vendor financing appears to be another option. However it is limited to only a few internationally recognized vendors who launch vendor finance programs. Vendor financing is preferred in situations where the project developer has limited borrowing capacity under the commercial financing regime to take on additional loans. In such cases, as the vendor supplies the equipment with payments spread over a period of time, vendor financing is preferred as it is not treated as debt and, therefore, does not count against borrowing capacity.

\section{Circularity}

Circularity implies a break with the linear "take, make, dispose" model that characterizes consumer behavior in society today, relying on large quantities of easily accessible cheap resources and energy. Circularity, or a circular economy, is an industrial economy that is restorative by intention; aims to rely on renewable energy; minimizes, tracks, and potentially eliminates the use of toxic chemicals; increases competitiveness and reduces costs; and minimizes waste through careful design (McKinsey and MacArthur 2012; 2013). Its principles have gained momentum and have successfully been implemented by the largest companies in the world (MacArthur 2013), economic zones in the Republic of Korea, China (Mathews 2011), Denmark (Kalundborg, n.d.), entire regions and cities (Geng et al. 2009; Sustainable Cleveland 2016), and across relevant sectors (Saito 2013). See Figure 3.3 for an example. 
Figure 3.3

Industrial Symbiosis in Kalundborg

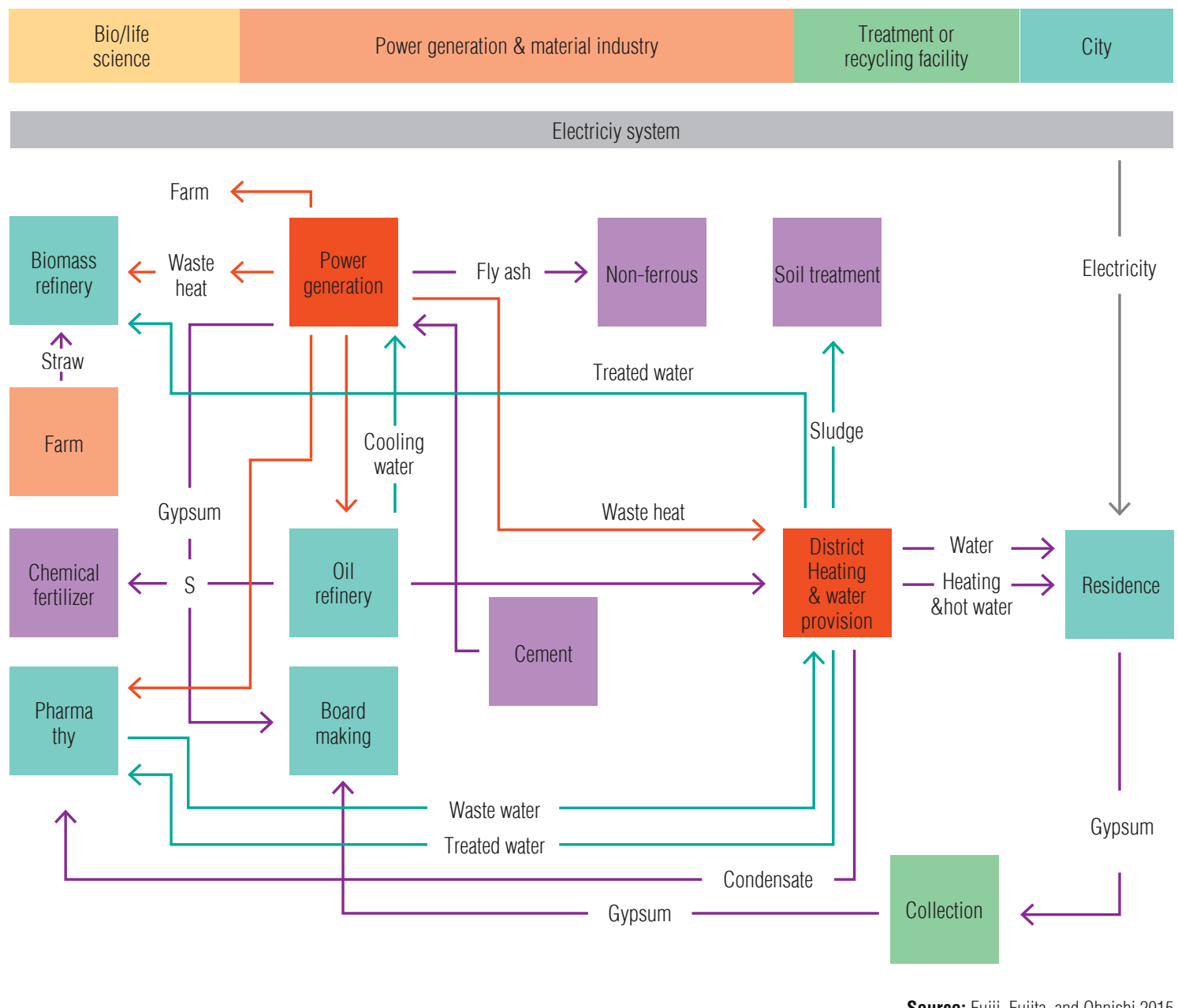

\section{Source: Fujii, Fujita, and Ohnishi 2015}

Within the EIP framework, waste and water management is the main driver for the circular economy at the industrial level. Utilizing water resources as efficiently as possible and turning large waste streams into material exchange paves the way for greening the industrial parks. Where it is technically feasible, circularity helps enterprises reduce operational expenses by lessening the amount of waste and water streams to be disposed of, transferred, or treated. Storm water as well as wastewater collection should be in place. A water circulation ratio can be used as an indicator of adherence to the EIP intervention. Waste circularity in terms of a hierarchal waste management approach is a part of circular economy and one of the technical opportunities to be applied by EIPs. Waste minimization at its source by selecting one of the technical opportunities to be applied by EIPs. Waste minimization at its source by selecting
appropriate raw materials to be processed and adapting low waste generation practices pertaining to appropriate raw materials to be processed and adapting low waste generation practices pertaining to eco-concept. Industrial symbiosis is used as a tool for circulating waste and having operators receive mutual benefit.

In the selection of individual waste management solutions, materials with high potential for reuse should be sought. The operator should consider recovery options for the waste such as metals or cooking oil. The waste should be recycled where reduce, reuse, or recover is not possible due to the nature of the process. The recycling service could be provided within the park operator's mandate or outsourced. If disposal is unavoidable, it is done based on the type of waste: hazardous or nonhazardous. As recommended within the World Bank Group Environmental, Health, and Safety Guidelines (1.6. Waste Management), periodic auditing by a third party of treatment and disposal services, including reuse and recycling facilities, is recommended when significant quantities of wastes are managed by third parties. Whenever possible, audits should include site visits to the treatment storage and disposal location.

Examples of Savings from Circularity and Symbiosis

Industrial symbiosis approaches industrial processes much like a biological or ecological system in which there is no such thing as waste and even waste has value, as it can be reused or recycled for utilization in other modes of production. In other words, the waste stream from one industrial process can be used as a material input for another industrial process. For example, a company that produces steam as a result of their production process could sell its steam to a nearby company that requires steam for energy or other proces steam tor en inceplon on the EIP. he laying of steam pipel ses such that resources lke steam may be shared smoothly am 3.4 schematizes an application of industrial symbiosis within an industrial zone.

On a national level, and from the standpoint of an industrial zone, the benefits of industrial symbiosis can directly be felt in the mitigation of waste and pollution from industrial production. For many developing economies, environmental degradation may be considered a necessary evil of muchneeded industrial development, and environmental and social concerns arising from industrial zones become secondary to the need for economic development. In the Republic of Korea, during the years of rapid economic expansion, this was mostly the case, and the benefits from productive industrial zones were deemed to outweigh the negative environmental impacts. However, growing awareness of environmental issues, climate change, and the increasing cost of energy made it necessary to find a more sustainable means of growth through industrial symbiosis. For industrial zones, industrial symbiosis created a way to maintain productivity while reducing waste and pollution. For countries like Pakistan or Egypt that face large-scale energy shortages, industrial symbiosis provides a potential source of energy, reducing the need for large-scale additions to generation capacity.

Figure 3. 4

A Schematic of Symbiotic Relationships

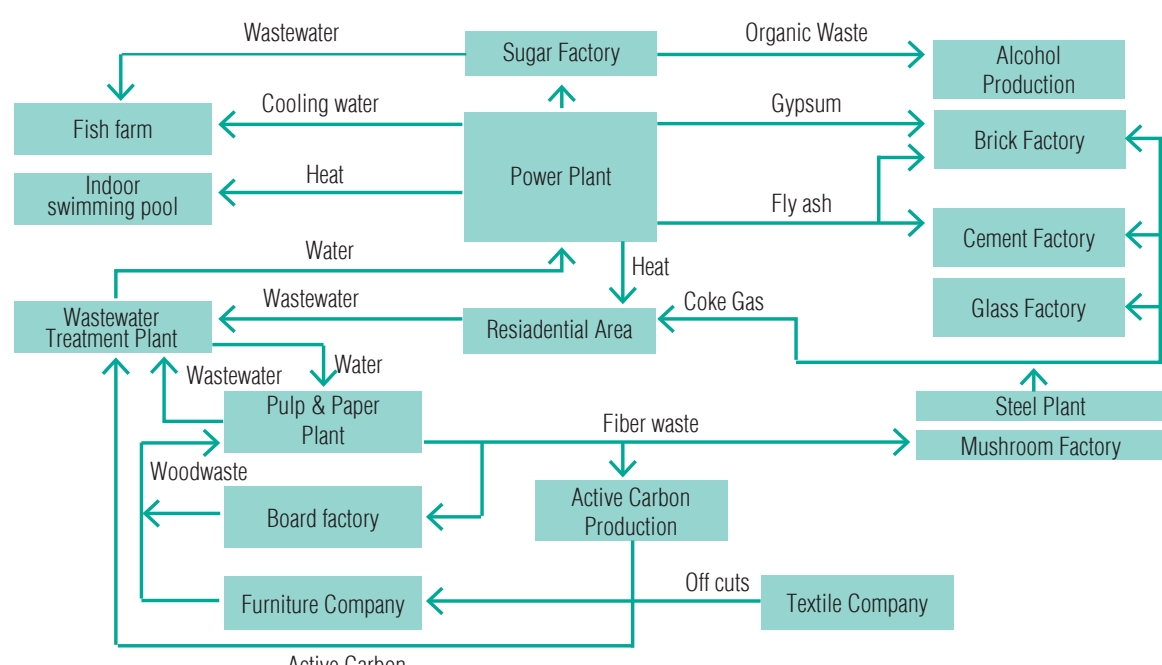

Active Carbon 


\section{Main Factors of Circularity Success}

Water circularity let zones to use water over and over again and cut down on operational costs while boosting resource efficiency. Waste circularity decreases demand for raw materials and increases firmlevel competitiveness.

In the case of industrial symbiosis in the Republic of Korea, a systematic approach to planning and implementation was integral to success. The approach, divided into scoping, negotiation, and business phase, incorporated participation from the government, development partners, and private sector partners (see Figure 3.5).

Figure 3.5

How to Carry Out an EIP Project

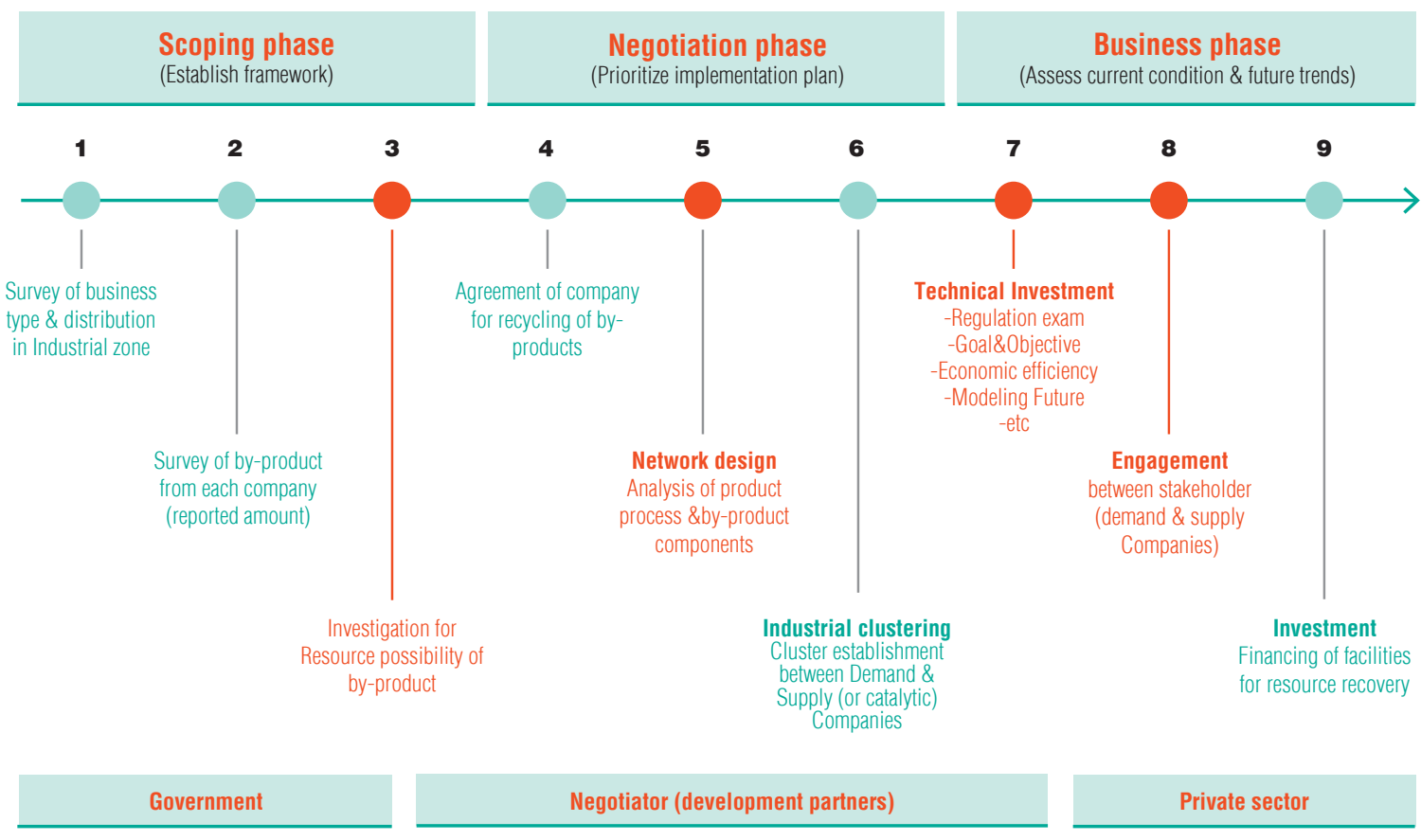

Source: Han 2015
Common Financing Opportunities in Circularity and Symbiosis

When an infrastructural investment such as steam highway pipeline or water circulation unit involves more than one firm's as well as the zone's interest, a PPP finance model is appropriate. Small-scale waste circularity among two or three tenants generally is financed commercially. When a purchase of equipment is in question, the developers tap into performance-based fiscal incentives. For example, the UK government started a program called Enhanced Capital Allowances (ECA) to encourage industries to shift into energy-saving technologies. On behalf of the government, Carbon Trust prepared a list of energy technologies to frame the options and ensure their reliability in energy savings. ECA allows businesses to write off the whole cost of the equipment against taxable profits in the year of purchase. This can provide a cash flow boest and an incentive to invest in energy-saving equipment, which normally carries a price premium when compared to less efficient alternatives. ECA can provide a cash flow boost of $\$ 1,040$ (about US\$2,300) for every $£ 10,000$ (US\$14,500) and it spends in the year of purchase.

In the Republic of Korea, an investment into an industrial symbiosis project had been made through In the Republc Though aiming to boost industrial competitiveness and energy efficiency as a leading industrial symbiosis project (Figure 3.6). The enterprises that would benefit from this investment could not afford to invest in the "Steam H.6. The enterpises that would benert rom his investment could not artord to invest in the Steam Highway Projecl individually. The project is a 6.2 kilometer-long pipeline consisting of several entrances and exis, facillating steam networking among companies in the area. In this PPP, the public sector invested US\$22 million through the Korea Industral Complex Corp (KICOX). The private sector contributed US $\$ 5.5$ million to participate in the network development and connect their own facilities. The steam supply enables SK Energy, the anchor participant in the pipeline, to save 49 milion tons of bunker C oil annually and avoid 100,000 tons of GHGs compared to the operation of SK Energy's own boilers.

Through this process, potential for shared waste streams and processes are identified along with the necessary infrastructure requirements. Although private firms initially showed hesitation in sharing data, the extensive negotiation process allowed them to understand the merits of participating in the development of industrial symbiosis and overcome barriers.

Circularity creates firm- and zone-level sustainability and decreases dependency on resources. Firms become more resilient to climate change, which increases their market competitiveness in the long run. 
References

E0-Industrial Park 2015 Conference

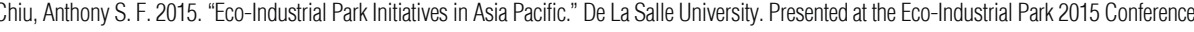

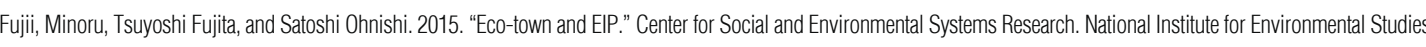

JAPAN. Presenented a th the ECo-Industrial Park 2015 Conferenene.

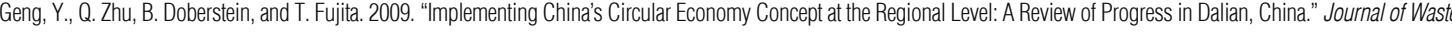
Management, 29(2): $996-1002$

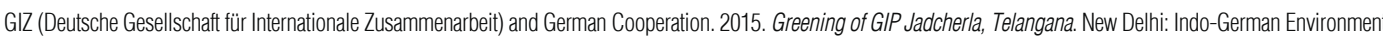

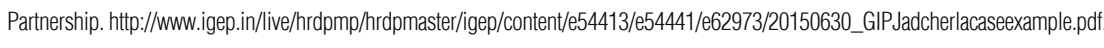

Han, Dukgyu. 2015. "The Problem \& Solution Strategeses for Industrial Symbiosis Network Development". Korea Industrial Complex Corporation. Presented at the Eco-Industrial Part 2015 Conference.

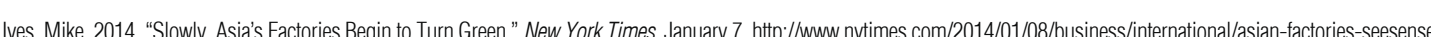

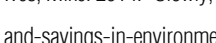

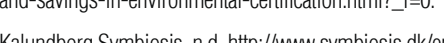

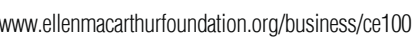

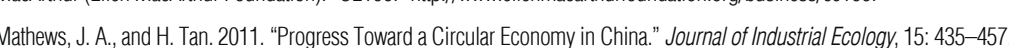

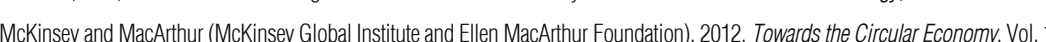

- 2013. Towards the Circular E Eonomy. Vol. 2.

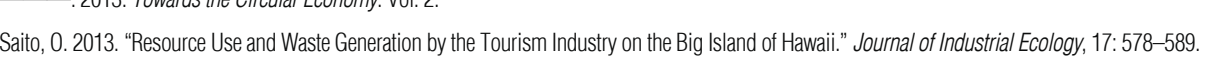

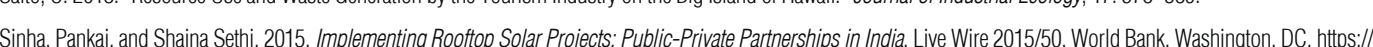

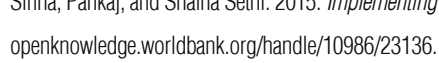

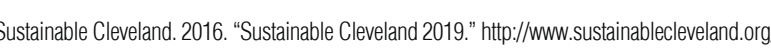

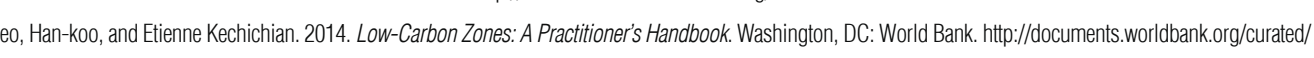

en/2014/05/20193042/10wearbon-zones-practitioners-handbook.

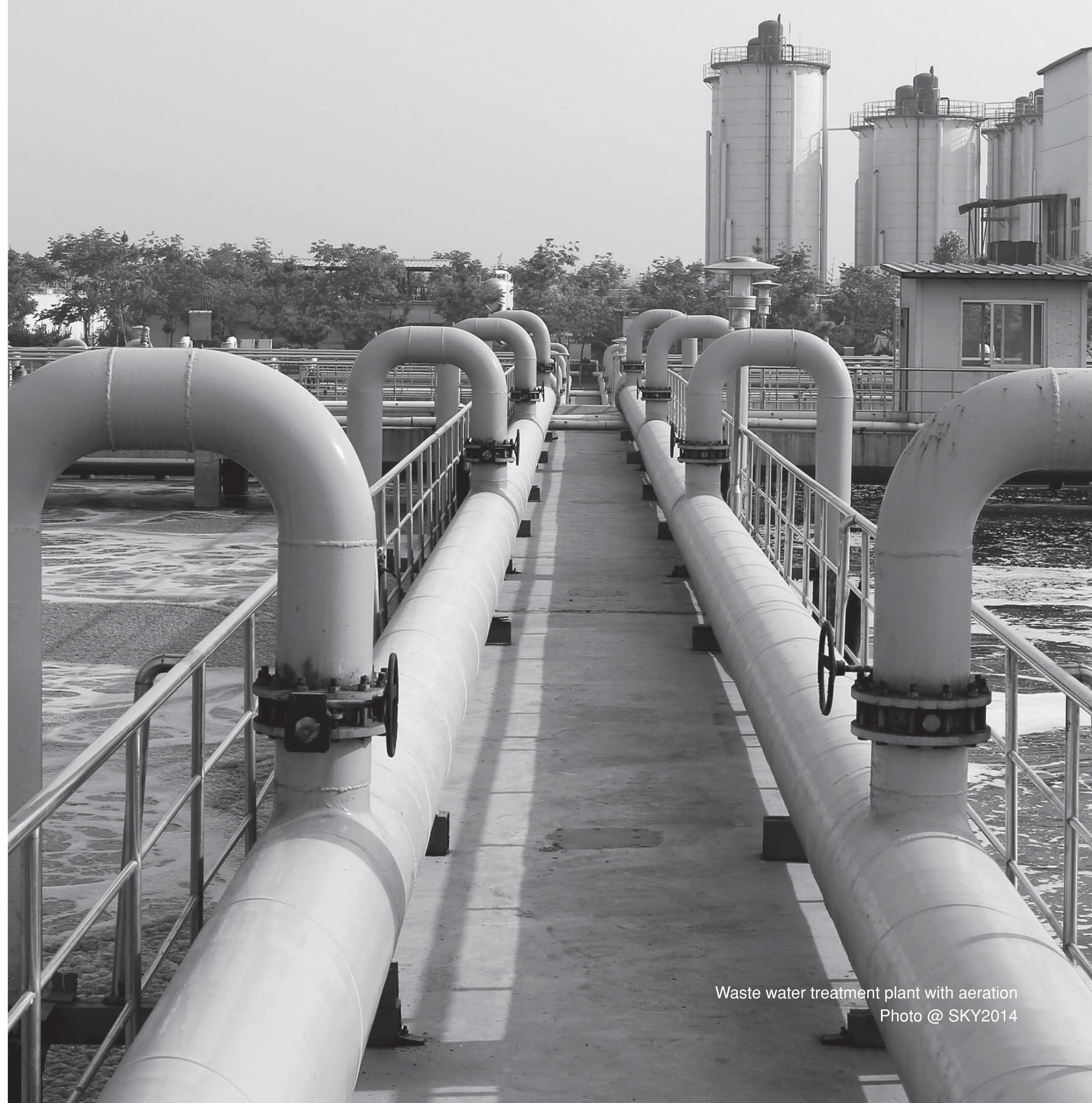




\section{Structuring the Approach}

The progression of Zone 1.0 through Zone 3.0 development and other adaptations of eco-industrial park (EIP) concepts in individual countries shows a trend toward a comprehensive approach to green development. This approach includes a wide range of stakeholders and aims to create social and environmental benefits as well as economic benefits. A plethora of resource management issues are being addressed and stakeholder participation is growing in quantity and variety-and policy makers and developers may find it daunting to navigate toward an EIP approach in this changing world. Taking a comprehensive approach means that multiple factors need to be considered when drafting policy, a large data base is requed, and mu cases illustrating how the approach has been used in different countries (Figure 4.1).

Figure 4.1

An Approach to EIP Development
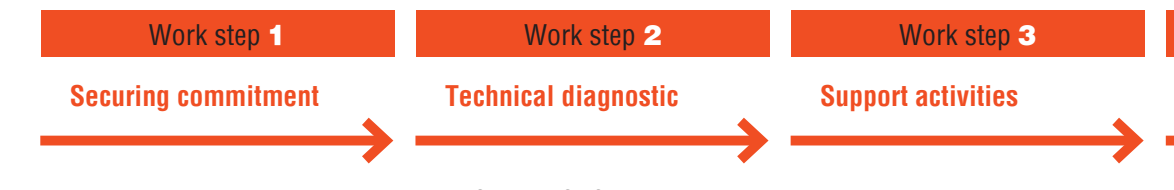

- Assess political economy o

- Establish organization and
- Conduct GHG inventory and forecasting

low-carbon developmen

- Identify stakeholders and

Conduct energy audit an

energy survey

leadership, reate a vision

- Conduct survey of waste/

byproduct production an

assess resource value

- Assess business case a

prioritize projects

- Develop detailed plan for

project implementation

- Project content an

Scheduling

Technology and vendor

selection

- Financing needs

- Training and manpower

$$
\text { needs }
$$

- Identify financing

mechanisms

Identify institutional and

- organizational needs

- Roll out projects

The International Finance Corporation's Low-Carbon Zones: A Practitioner's Handbook (World Bank 2014) and Deutsche Gesellschaft für Internationale Zusammenarbeit's (GIZ's) Guidelines for Sustainable Industrial Areas (GIZ 2015) are tools that outline how to design, develop, and implement an EIP concept. This section provides a brief synthesis of these approaches to EIPs. (Box 4.1 on Guidelines for Sustainable Industrial Areas) enterprises and projects Develop stakeholder
reporting structure - Publish / circulate report

\section{Box 4.1 Sustainable Industrial Areas}

As one of the mentioned approaches to mainstream Eco-Industrial Parks, the Deutsche Gesellschaft für Internationale Zusammenarbeit (GIZ) GmbH, promotes the idea of "Sustainable Industrial Areas" (SIA). The growth of the industry sector is now an essential part of the Sustainable Development Goalsa. The idea of "Sustainable Industrial Area" reflects this orientation and includes social aspects next to organizational, environmental and economical features as an

indispensable requirement for a park on its pathway to sustainability.

Various experiences in partner countries revealed a main challenge in planning and realizing an EIP/SIA is due to lacking comprehensive approaches and unclear national standards and policies, besides missing competencies and management structures to operate such industrial parks. These inadequacies cause a decrease in competitiveness and attractiveness of industrial areas to private investors, besides posing concerns of environment pollution, climate change and resource efficiency.

The success of sustainable industrial areas depends significantly on the quality of the standards which are used for planning them. Towards this, GIZ supports several countries on macro-level to define sustainability of industrial areas and formulate standards or guidelines for promoting sustainable industrial areas (e.g. Indonesia, Morocco and India).

Besides this, accompanying site master planning and

management structure processes of industrial areas

are a core element of GIZ's approach towards SIA. As a successful showcase, the ALEAP Green Industrial Park Jadcherla in the State of Telangana, illustrates how planning of gender inclusive and environment friendly site master planning in industrial parks is possible. GIZ provided technical support to the Association of Lady Entrepreneurs of Andhra Pradesh (ALEAP) for site master planning of the Green Industrial Park (GRIP) project to women entrepreneurs. Several aspects of environment. economic quality, resource efficiency, cost-effective common infrastructure, social aspects and gender aspects were integrated into to the planning of the industrial park

Furthermore, to strengthen the sustainable industrial areas, on company level, GIZ applied methodologies like areas, on company level, GIZ applied methodologles like Pro and ECOPROHT to help ind indual companies housed in the industrial areas to identily cost effecive options for mproving their environmental and resource management performance.

GIZ has recently (2015) published a "Guideline for Sustainable Industrial Areas" that highlights the most important sustainability aspects for planning and operating an industrial area. These guidelines are directed to industrial park operators, planners of industrial areas, public administrators in charge of regulating industrial areas and experts advising on industrial development.

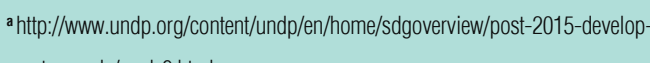
ment-agenda/goal-9.html

In step one of the process, the goal is to gain political commitment and support from international development partners and, in some cases, from the central government. Existing national strategies or goals and the broader political agenda of the government need to be assessed in order to determine whether there is an institutional framework supportive of EIPs already in place, or how EIPs may work to support the broader national development agenda. This stage must also be used to identify the key challenges in committing resources and implementing EIP in order to identify the different public sector, private sector, and community stakeholders.

Based on these assessments, an organizational framework should be developed to gain national and subnational support for EIPs. Relevant Ministries should be consulted and a central execution agency should be designated. In countries where there are existing zone authorities, such as the Korea Industrial Complex Corporation (KICOX) in the Republic of Korea or Bangladesh Export Processing Zones Authority in Bangladesh, these authorities (if not already taking the lead) should be designated as the focal points. Additionally, key industry leaders or industry associations should be identified to work together as a private sector rallying point. Roles and responsibilities of these participating stakeholders need to be clearly set, 
with the first task being to set a vision statement for the zone. The vision statement should express a clear objective, such as resource efficiency maximization, linked to the zone's overall economic objectives. The leading stakeholders will need to work with other stakeholders to ensure there is broad support within in the zone from firms, utilities, and the community.

Step 2 will run diagnostics to ascertain the current status of carbon and resources in the zone. Audits to develop a resource-use inventory and forecast future uses as well as energy audits and energy surveys will identify the areas that need improvement. During these audits, an inventory of the waste streams needs to be built, and assessment should be made of which waste or production byproducts may have value as energy or material inputs for other firms in the zone. An analysis of carbon, energy, resources, for industrial symbiosis.

The audits will allow Special Economic Zones to assess possible business opportunities to create a pipell rechnical requirements, potential benefis, and potntial bariers mus be an alyzed in order to prioritize partners and consultants.

Step 3 can largely be divided into planning, identification of financing mechanisms, and the rollout phase. The planning phase entails creating a detailed plan for project implementation, including the content an schedule for implementation and listing the technological, financing, and manpower needs. The project mplementation plan must be aligned with the zone's goals for resource efficiency and must be based on design and feasibility study to cover the technical aspects of the project.

Identifying and addressing financing needs is crucial for project implementation. During step three, the plan must first identify how much funding is necessary and what funds are available to meet these needs. How much of the needs can be met through the participating firms' own equity and how much external funds are necessary needs to be answered first. Identification of fiscal incentives made available through the government, market-based financing, or international tools such as Clean Development Mechanism will need to be part of the implementation plan. Various mechanisms discussed in this report such as public-private partnerships or an energy service company may be considered, depending on local market conditions

In line with identification of financial needs and available resources, the EIP implementation plan must consider institutional and organizational needs as well as manpower needs. As is clear from step one in Figure 4.1, clear leadership and initiative along with data collection and analysis are key to implementing EIP projects
Figure 4.2

KICOX Regional EIP Institutional Structure

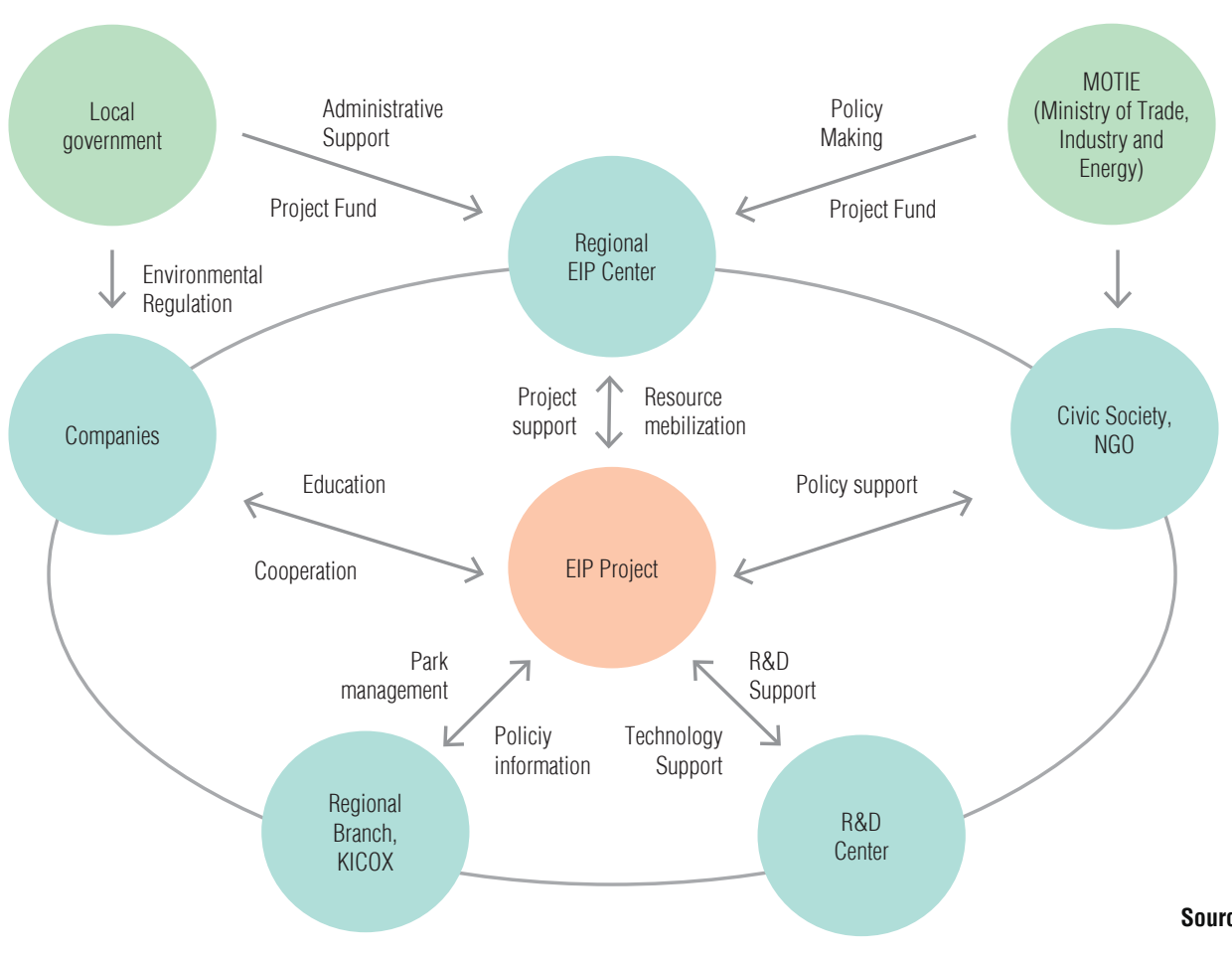

Source: Park 2015

For many developing countries, the EIP is still a new concept, and centralized management of zones may still be in its infancy. The implementation plan needs to incorporate measures to strengthen the institutiona capacity of the implementing agency. In addition, for firms to effectively participate in the EIP and benefit, they must build the capacity to manage resources systematically and be able to collect and report data for in-house analysis and reporting to the zone authority for management. Therefore, building organizational capacity and securing the manpower needed to manage data and implement changes within the production process are integral parts of planning for EIPs. Figure 4.2 provides an example of an institutional structure for the EIP process.

In step four of the implementation process, a system to monitor performance after project rollout needs to be established. It can be an IT-based system that stores and analyzes data provided by various participating firms in order to assess whether resource efficiency targets are being met and help calculate the economic and environmental benefits (or costs) from the project. The data can be used to identify areas for

improvement and report performance to the central government or development partners for further support. Key findings can be circulated amongst stakeholders to promote further discussion and awareness for ElPs. Key findings can be circulated amongst stakeholders to promote further discussion and awareness for EIPs. In addition, successful performance reports can benefit individual firms competing in the global market as part of their corporate stewardship efforts.

The four development steps are based on retrofitting or adjusting an existing zone into and EIP. In some cases, governments may wish to incorporate EIP when planning the development of a new industrial zone. In this case, it will be beneficial to consider which industries to focus the zone on and select industries that promote the green economy factors, such as alternative energy use or energy efficiency measures. Selecting industries that would promote green growth while still being in line with the regional and national economy's core competencies will precede the four steps. Then, rather than diagnosing existing firms environmental 
and economic performance, it will be necessary to forecast the resource potential of the firms that wish to enter the zone. Their resource use and waste streams should be assessed along the supply chain and firms can then be clustered for easier resource recycling.

Based on the characteristics of the national economy or a particular zone, particular tools and techniques can be used in implementing a version of the four-step framework. Some key innovations and practices from current EIP efforts are illustrated below.

EIP for national competitiveness: Guatemala. The government of Guatemala has been promoting EIPS as a way of reaching national goals of attracting foreign investment, creating jobs, and supporting local governments. With 17 active Free Economic Zones in place, four townships have become EIP zones. Currently, in the township of Estanzuela, the EIP is expected to provide more than 3,000 formal employment opportunities. As per step one of the EIP approach, the city has identified Pronacom as the implementing agency and has set goals to create a zone with low emissions, energy optimization, eco-friendly practices, economic stability, and social and environmental sustainability. The next steps planned for the proctices the industries (dingnostics), update budgetary needs (financia planning), and present ma updated model bed on the diagnostics (implementation planning).

Focus on a specific stakeholder Group: India. In step one of the EIP approach, identifying stakeholders and designating a particular group as a rallying point or a private sector focal point for building commitment and engaging the private sector was discussed. In India, the Association for Lady Entrepreneurs of India has taken this role in working with GIZ on eco-friendly industrial parks. In the Dr. A.P.J. Abdul Kalam Green Industrial Park in Nandigama Villag, located in the Medak District, the EIP has focused on an important segment of the economic population: women. The association has helped to create a vision statement (discussed in step one), which outlines goals for the park to "design an eco-friendly and self-sustainable industrial development" that provides a conducive environment for female entrepreneurs. Industrial plots have been divided into clusters of different industries based on emissions and waste and common areas with shared resources such as waste management and business incubators. The development aims to provide social benefits to the community, supporting over 100 women from below the poverty line and the middle class in entrepreneurship and creating 8,000 jobs for the community, with an expected indirect benefit to 24,000 people.

Expanding the boundaries of EIP: China. The Dutch-Sino Smart Industrial Park project currently under way with funding from the Netherlands Organization for Scientific Research (NWO) and being implemented jointly by the Technische Universiteit Delft and Chongqing and Tsinghua Universities aims to develop a model of ind ctria symbiosis for the more than 100 EIPs being designed in China The project broaden the boundaries of EIPs by connecting the material flow and life-cycle analysis of the industria park to tha

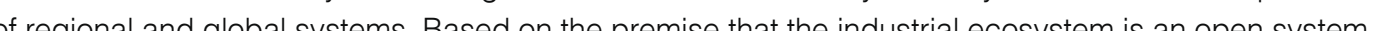

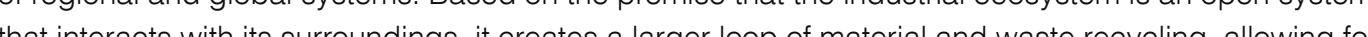
consideration of larger impacts of EIPs. Though this project is still in the design phase, it shows the potentia for creating numerous benefits for the community and economy outside of the EIP itself, if the industrial for creating numerous benefits for the community and econ

It is important that the specificities of the national and local economies and the characteristics of the loca Industry are kept at the forefront of decision making when planning an EIP. No two economies are identical and simply trying to copy one successful model may not have the desired results in an economy with vastly different conditions, different areas needing attention, and different stakeholder groups. However, the steps taken in the cases presented can provide a framework for understanding and incorporating specificities into the planning process.
References

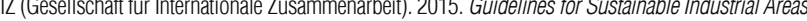

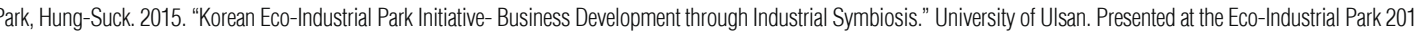
Conference.

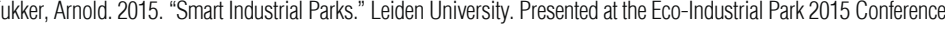

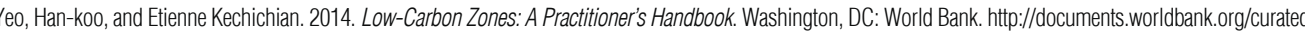
en/2014/05/20193042/1/owcarbon-zones-practitioners-handbook. 

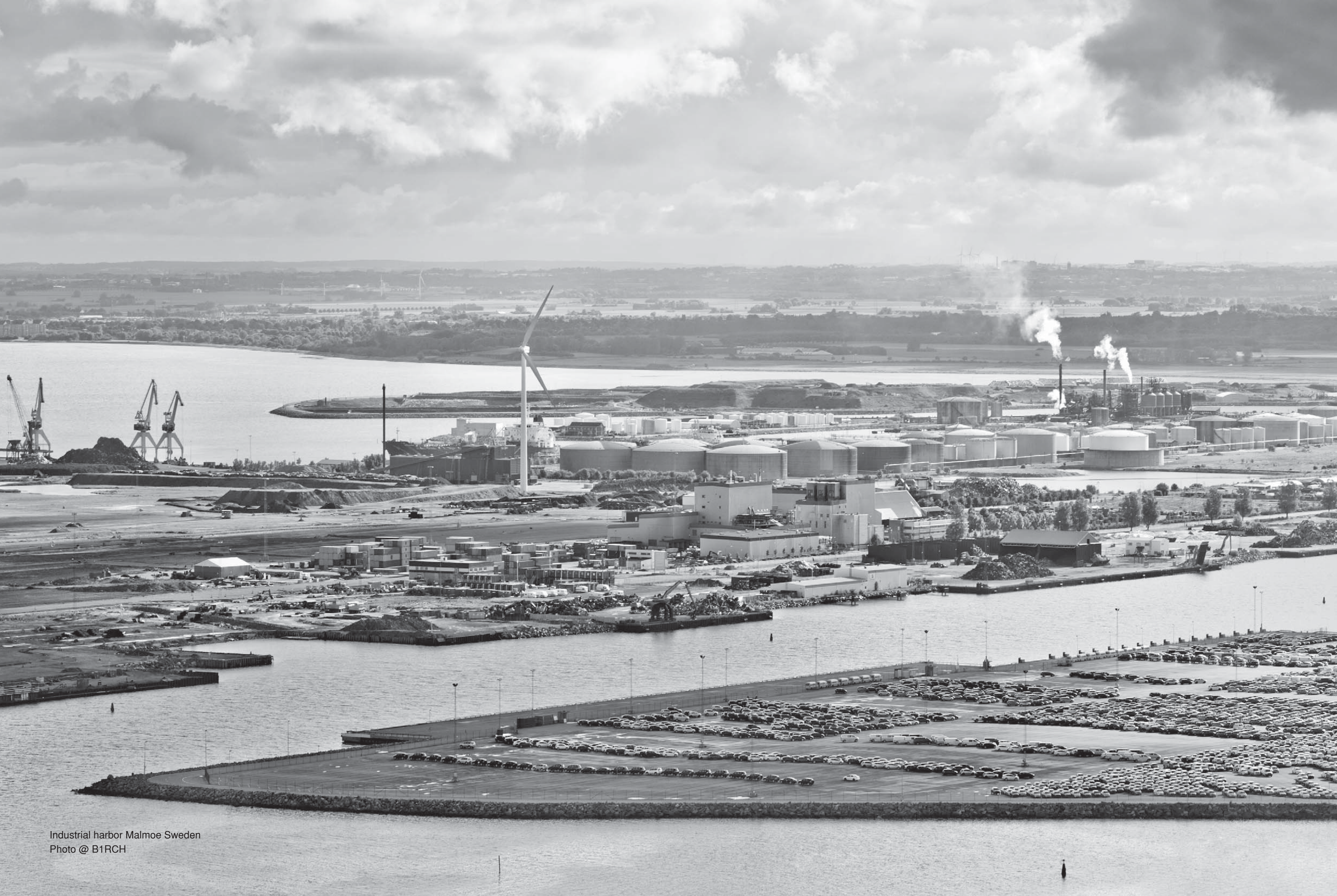


\section{Conclusions and the Next Trends of EIPs}

As environmental externalities become a bigger factor in business operations and decision making, we will continue to see an increase in trends for eco-industrial park (EIPS). Global factors will help spur EIP growth to a higher level. The factors will include such things as a common price on carbon and national commitments to mitigation and adaptation-and more importantly their implementation. To complement these market drivers, the international community and industrial park investors need to take the initiative to develop a
common understanding of EIPs and their technical requirements. This needs to be complemented by national fremon the regulations to form a baseline for EIP growth.

A common understanding of what it means to be an EIP will greatly help catalyze and mainstream the EIP concept. The current global framework for EIP and lack of standards delay trust in the concept and prevent the EIP "brand" from being a market driver. It is therefore recommended that a common framework should be developed that provides developers and operators and the international community with a certain level of confidence to the concept of an EIP (Van Berkel 2015) This common concept should include the core strengths and opportunities of Zone 3.0 and include (i) clean energy, (ii) resource efficiency and cleaner production, and (iii) circularity, and eventually (iv) green design.

These areas of focus should be accompanied by the development of indicators that industrial park operators and developers can use in order to measure and promote their accomplishments. In the research literature there are few studies that aim to set particular indicators for EIPS, and most of them are influenced by regional industrial parks as a starting point. For instance, the Chinese Environmental State Agency (SEPA) is influenced by local Chinese industrial parks while setting EIP criteria. Koenig conducted his study in scope of Thai industrial parks to improve a set of criteria for Thai EIPS (Box 5.1) (Koenig 2000).

\section{Box 5.1 Examples of EIP Guidelines}

\section{China's SEPA Criteria a}

In 2006 the Chinese Environmental State Agency (SEPA) developed criteria for EIPs. SEPA emphasized a collaboration between companies and/or plants that hinged on resource sharing and waste exchanges that targeted resource efficiency and waste minimization

The companies' collaboration would be similar to

a natural system-a circular industrial path of

"producer-customer-decomposer." SEPA classifies the main characteristics of an EIP under four criteria.

1. An eco-industrial park is a complex of nature, industry, and society.

2. An EIP strives to achieve the maximum use of resources and minimum discharge of waste through the exchange of by-products and wastes, circular use of energy and wastewater, and the sharable use of infrastructure among the processing units of the industrial park.

3. An EIP intends to ensuring the steady and sustainable development of the industrial park through the application of modern administration, policy, and new technology with the aim of sharing information, saving water and energy, recirculation and reuse, environment monitoring, and sustainable transportation methods.

4. Through effective construction and operation of the park's infrastructures, the environmental conditions of companies, the reach a sustainable improvement. park, and the whole community will
These characteristics will be achieved through six principles: should be connected with the regional natural ecosystem to maintain its eco-functions as natural ecosystem to
much as possible.

2. Eco-efficiency principle: Carry out clean production concepts when designing the park. constructing infrastructure and buildings, and operating production. administration of the raw materials before they they leave the park in order to minimize the negative environmental effects along the product and waste life cycle.

4. Regional development principle: Integrate the ecoindustry park with regional development and characteristic economy; integrate the construction of the eco-industrial park with the renovation of the regional eco-environment.

5. High-tech and high-benefit principle: Broadly use for energy savings, water saving, recycling, and information sharing; advanced production administration; and environmental administration criteria.

6. Pay equal attention to software and hardware principle: Hardware refers to the construction plan of projects, including industrial facilities, infrastructure, and service facilities.Software includes the establishment of an environmental administration system, construction of an information support system and enactment of preferential policy, which can support healthy and sustainable development of the EIP.
1. Natural ecosstem principle Eco-indstia pars

3. Life-cycle principle: Intensify the life-cycle enter into the park and products and waste after modern bio-techniques; eco-techniques; techniques

\section{Koenig's Criteria for Thai EIPs}

Koenig in 2000 improved a set of 5 criteria and 22 subcriteria to define EIPs in Thailand. In accordance with Koenig's approach, to be called as EIP a park should be in compliance with criteria that addres physical, economic, environmental, social, and

internal management objectives.

1. Physically, parks must be developed with infrastructure in public utilities and facilities that is environmentally sound, sufficient, efficient, and safe.

2. Economically, the park has to promote local and provincial economies.

3. Environmentally, within the park, operating industries must utilize energy and resources in an efficient manner during production processes, promote waste reduction, and produce environmentally friendly goods.

4. Socially, the managing organization has to execute human-focused management that makes the welleing of people in the organization the top priority and must be a significant participant in creating a good quality of life for the community.

5. The park management must focuses on collaboration and good governance for the benefit of all parties involved.

China's Guidelines for eco-industry park planning, An Indigo Industrial Ecology Paper, http:///www.indigoder.com/sep__eip__uideline. hit

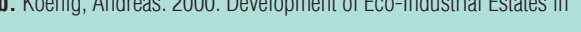
Thailand, Project Develoopment and Appraisal, June to December 2000. GTZ tor Industrial Estate Authority of Thaliand.

In order to enable comparison of EIPs and form a global framework, a holistic and easily measurable approach should be developed. It should be flexible to allow for different types of policy goals to be integrated (carbon emissions, social and environmental health and safety, and so forth), allow for ease of data collection, and ensure that it is progressive in terms of allowing the industrial park to increase its ability to meet ecological goals

Within the Zones 3.0 framework, one can expect more integrated and smart systems to promote EIP ideas. The eco-town concept in Japan is looking to smart and interlinked systems to optimize the EIP concept (Figure 5.1). This would connect different energy systems to each other allowing for an optimization of material and energy use within the eco-city (Fujii, Fujita, and Ohnishi 2015). 
Figure 5.1

Smart Symbiosis Initiatives for Eco City Innovation

Smart ICT network will promote and complement

$\longleftrightarrow$ Actuation $\longleftrightarrow--\rightarrow$ Waste \& Mater the synergetic network functions among stakeholders

$\longleftrightarrow$ Energy $\longleftrightarrow--->$ Intormation

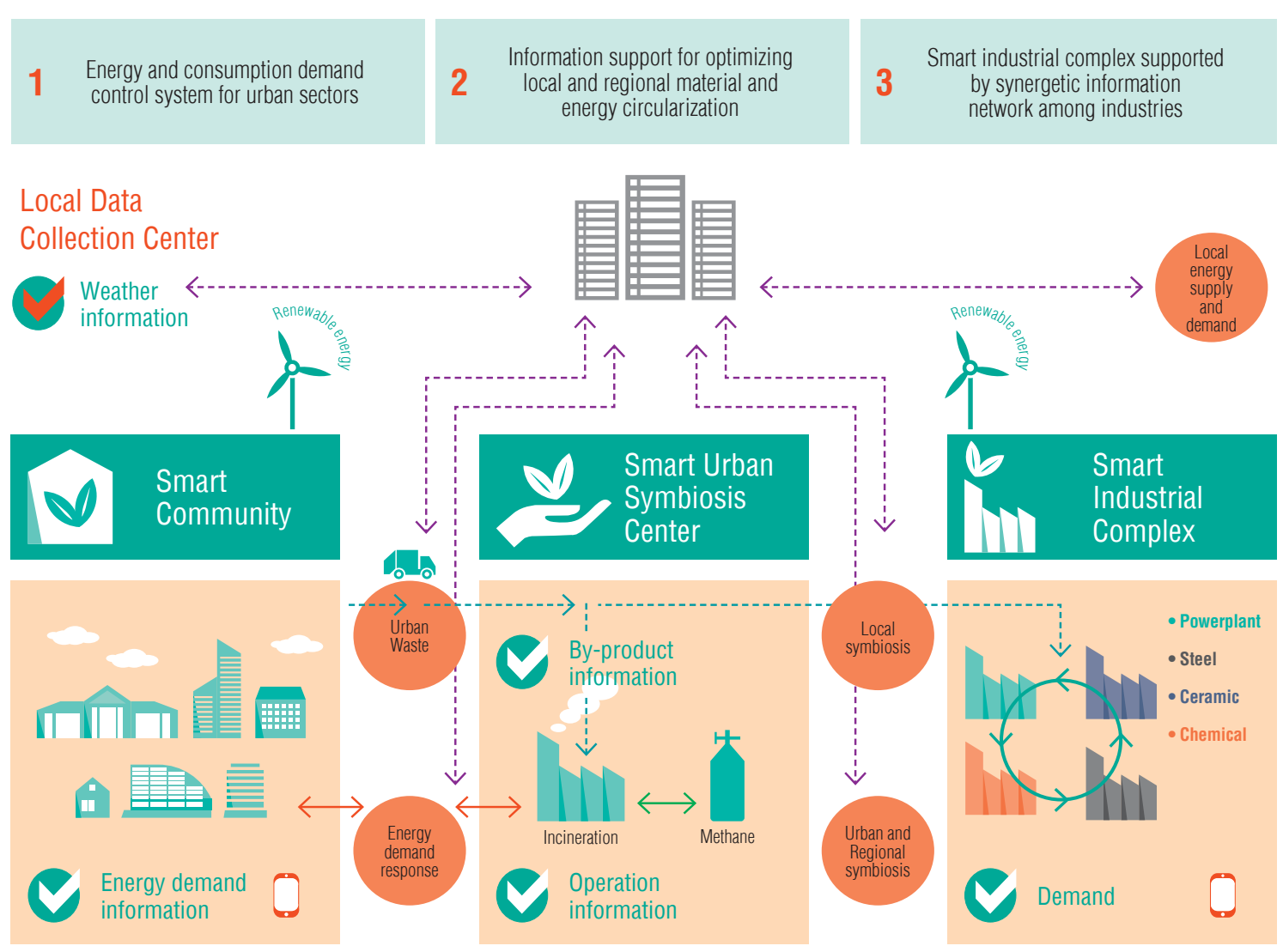

Source: Fujii, Fujita, and Ohnishi 2015
The Advent of Climate-Resilient Industrial Parks

The next generation of industrial parks will be those that provide enhanced climate resilience. Industrial parks will move beyond the EIP concept and into an industrial environment that helps companies manage and mitigate risk. A number of factors will play into this dynamic:

- There is a growing demand to integrate risk into infrastructure development due to climate change impacts. - Businesses now perceive climate risk as a top business risk for the first time (WEF 2015)

- Demand for infrastructure is high: $\$ 90$ trillion in low-carbon, climate-resilient infrastructure investment will be needed by 2030, mostly in developing countries.

- Current focus on resilience is on urban and social challenges. More focus is required to integrate economic equations into adaptation and mitigation.

- Industrial infrastructure and zones offer a cost-effective way to manage risks for industries and are vastly underutilized.

The 2011 floods in Thailand caused a loss of US $\$ 45.7$ billion - approximately 5 percent of gross domestic product, of which US $\$ 32$ billion can be attributed to losses in manufacturing. Floods in Chennai, India, in December 2015 caused a total of US $\$ 2.2$ billion in losses in the automotive sector and severely disrupted Chennai's burgeoning information and communications sector. Since those floods, Ford, Daimler, Apollo Tyres Renault-Nissan, BMW, and Hyundai Motors have all halted production in Chennai. The 2014 floods in the Balkans affected 19 percent of manufacturing units in Serbia alone. The Serbian manufacturing sector faced US $\$ 77$ million in damages and US\$89 million in overall economic losses, coupled with a total of US\$95 millio for the costs of recovery and reconstruction.

The number of climate-related disasters is growing. Countries that have been able, thus far, to avoid climate disaster are still at risk. In Vietnam's Ho Ci Minh City, 61 percent of urban land use and 67 percent of industria land use is expected to be flooded by 2050 if proposed flood-control measures are not implemented. In addition, 50 percent of industrial zones are at risk of flooding due to extreme events, even if the proposed flood-control measures are in place. An additional 20 percent of industrial parks are located within one kilometer of areas likely to suffer inundation.

This intensifying threat requires governments and the private sector to take action to promote climatecompetitive industries that can propel sustained economic growth. Measures that industrial parks take in order to help improve industrial resilience include the following:

- Develop a disaster-risk response that incorporates economic losses into planning for a second response to huma a dis cir 2010 earthalak in

the country helped the country retain supply-chain investors, create jobs, and revive economic grow

- Build better industrial park infrastructure and upgrade what currently exists. According to the World Economic Forum, the global infrastructure gap is estimated at US $\$ 3.7$ trillion annually, with only US $\$ 2.1$ trillion is invested each year (Figure 5.2) (WEF 2015). The demand for infrastructure should take into account disaster risk and vulnerability, requiring governments to make smart decisions about the type of infrastructure and its performance under increasing climate stress. As described by the WEF, this can be done by reducing demand, building new assets, and optimizing existing assets

One can look at this from a climate perspective by focusing on promoting eco-industrial development which by reduces resource use and promotes circularity to reduce infrastructure demand; by working with the private sector to ensure that new industrial infrastructure integrates climate risks and shocks; and by reviewing existing port and transport infrastructure for risks and vulnerabilities. 
Figure 5.2

Closing the Global Infrastructure Gap

\section{The global infrastructure ga}

in US\$ trillion, annual (average 2010-2030)

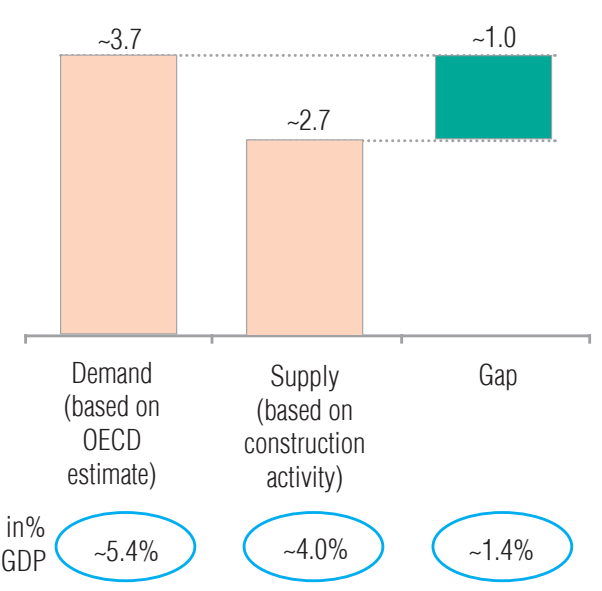

\section{Three levers to close the gap}

Infrastructure asset demand/supply

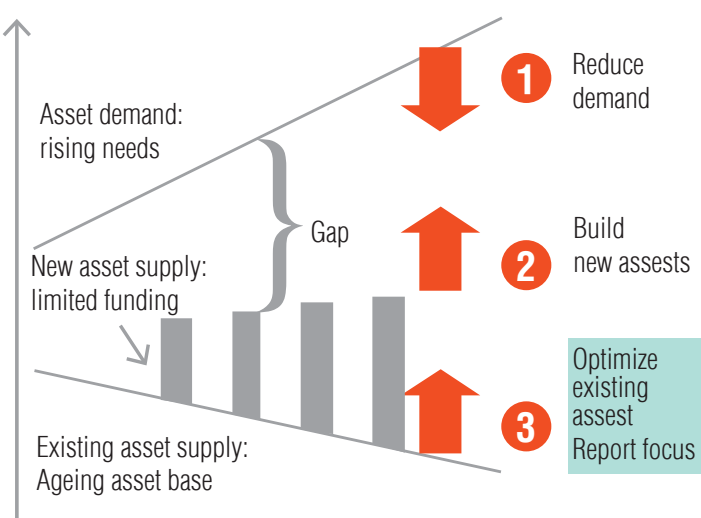

Time
References

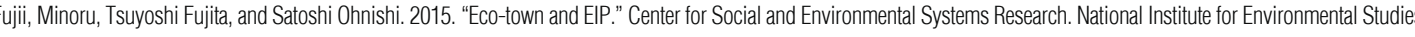
JAPAN. Preseneted at the Eco-Industrial Park 2015 Conference

政

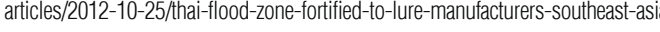

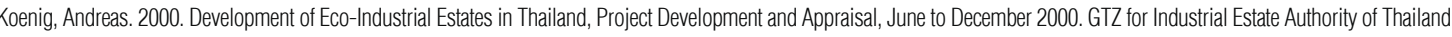

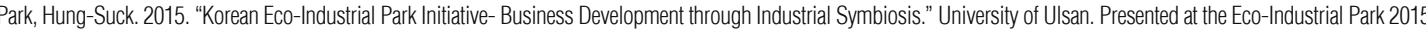
Conference

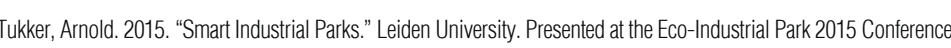

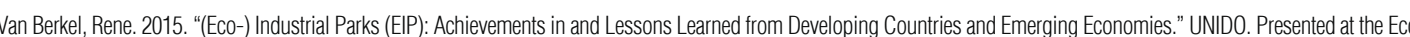
Industrial Park 2015 Conference.

WEF (Word Economic Forum). 2015. Strategic Intrastucture: Steps to Operate and Maintain Intrastructure Efficiently and Eftectively

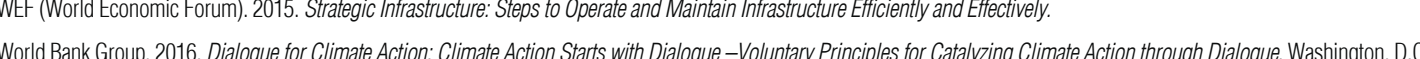
Wul action-through-dialogue.

- Engage in meaningful public-private dialogue to identify business challenges and concerns and to help prioritize climate-related measures. More than ever, preparing for broad-scale climate change, with its many cross-industry implications, requires public-private dialogue to help build trust, close the knowledge gap, catalyze action, and generate a sense of shared ownership. Among the key objectives of effective dialogue will be the following:

- To promote voluntary actions that the private sector, the public sector, and citizens can undertake

- To advance legal and regulatory reforms to encourage innovation, to promote the use of new technologies and inputs, to incentivize public-private partnerships, and to reward positive behavior while penalizing negative behavior

- To ensure the availability of and access to finance for businesses and citizens who will be ffected by climate change To pursu by climate change

encourage behavioral change-such as the "Principles on Dialogue for Climate Action" (World Bank Group 2016).

The approach to climate resilience complements the EIP framework. EIPs help reduce the use of resources and therefore minimize firm and industrial park exposure to resource disruption or volatility. The added focus on resilience will ensure that, not only does the industrial park contribute to lowering emissions, but it is attuned to the new climate reality and provides an extra value or service to its residents. For example, in Thailand, Rojana Industrial Estate completed a 75-kilometer concrete wall in 2013 to protect the 213 factories in the zone and to reassure and attract investors (Kate and Suwannakij 2012) 


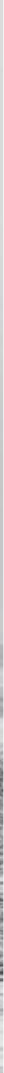

= 


\section{Mainstreaming \\ Eco-Industrial Parks}

July 2016

Etienne Kechichian

Mi Hoon Jeong

This report, based primarily on findings from a global conference "Eco-Industrial Parks 2015," held in Seoul, Republic of Korea in October 2015, provides the latest thinking on eco-industrial parks, bringing together experiences from different countries and providing a vision on how these initiatives can be scaled up or mainstreamed. It will provide policy makers with insight conceptualizing EIPs and what different factors need to be considered in putting together an EIP program. The report builds the basis for further development of global guidelines for EIP development and provides a brief insights into future trends on smart/ integrated industrial areas and climate resilient industrial parks. 